\title{
An electronic and vibrational study of the cyclopropenyl ion and its fluoroderivatives
}

\author{
Sérgio E. Galembeck ${ }^{\mathrm{a}, 1}$, Rui Fausto ${ }^{\mathrm{b}, *}$ \\ "Departamento de Quimica Fundamental, Universidade Federal de Pernambuco, Av. Luis Freire sin, Recife - PE, Brazil

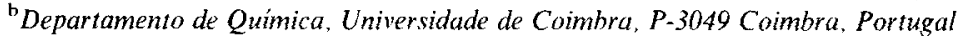

Received 16 May 1994; accepted 6 June 1994

\begin{abstract}
This article presents the results of ab initio SCF-MO calculations on both the electronic structure and vibrational spectra of the cyclopropenyl cation $\left(\mathrm{C}_{3} \mathrm{H}_{3}^{+}\right)$and its fluoroderivatives, $\mathrm{C}_{3} \mathrm{H}_{2} \mathrm{~F}^{+}, \mathrm{C}_{3} \mathrm{HF}_{2}^{+}$and $\mathrm{C}_{3} \mathrm{~F}_{3}^{+}$. A very simple and unambiguous criterion for choosing the combination of diffuse and polarization functions which, logether with the 6$311 \mathrm{G}$ basis set, best describes the electron distribution in these ions is presented. The electronic structures of the cations are analysed in detail; particular emphasis is given to the analysis of the electronic effects due to successive hydrogen-byfluorine replacements. The results of vibrational normal mode analysis carried out for all hydrogen-deuterium isotopomers of the studied ions are presented and compared with the available experimental data. The theoretical results are used both to review some band assignments previously proposed for the fluorosubstituted molecules and to give a stronger theoretical foundation to the general interpretation of the vibrational spectra of these compounds.
\end{abstract}

\section{Introduction}

The $\mathrm{C}_{3} \mathrm{H}_{3}^{+}$ion has received considerable attention in recent years due to its high abundance in oxidative flames [1], and because it has been suggested as a possible soot precursor [2-4]. Recently this ion was detected in the coma of comet Halley, its probable origin being the dust particles around the comet [5]. Experimentally, two isomeric structures of $\mathrm{C}_{3} \mathrm{H}_{3}^{+}$were observed: the cyclopropenyl (CP) and the propargyl cations [6,7] (Fig. 1), the

\footnotetext{
* Corresponding author.

' Permanent address: Departamento de Quimica, Faculdade de Filosofia, Ciências e Letras de Ribeirăo Preto, Universidade de São Paulo, Av, dos Bandeirantes, 3900, 14040-901 Riberão Preto - SP, Brazil
}

first corresponding to the most stable isomer $\left(\Delta E=109 \mathrm{~kJ} \mathrm{~mol}^{-1}[6]\right)$. Theoretically, CP was also found to be the global energy minimum [8-12].

Because it is the simplest aromatic system, with two $\pi$ electrons, CP presents great theoretical interest. In addition, it also exhibits $\sigma$-aromaticity, a property which is characteristic of three-membered cyclic systems. Indeed, both these factors contribute to stabilize this highly strained compound.

In the mid-fifties several derivatives of $\mathbf{C P}$ were prepared. However, only twenty years later were salts of the non-substituted ion isolated [13]. The large ${ }^{13} \mathrm{C}-\mathrm{H}$ coupling constants observed for these systems suggested that the $\mathrm{C}-\mathrm{H}$ bonds in $\mathbf{C P}$ should involve a carbon sp hybrid orbital. Thus, it was proposed that each carbon atom uses an $\mathrm{sp}$ 


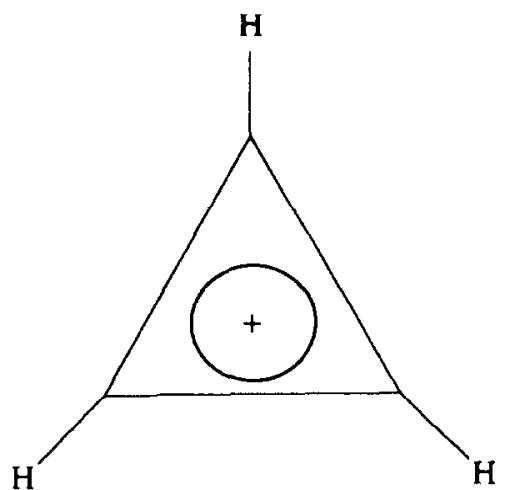

CP

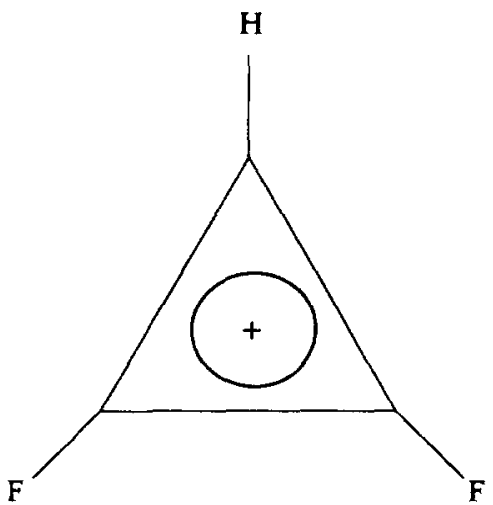

DFCP

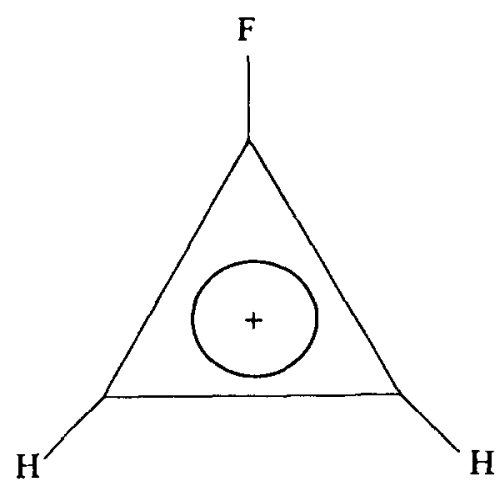

MFCP

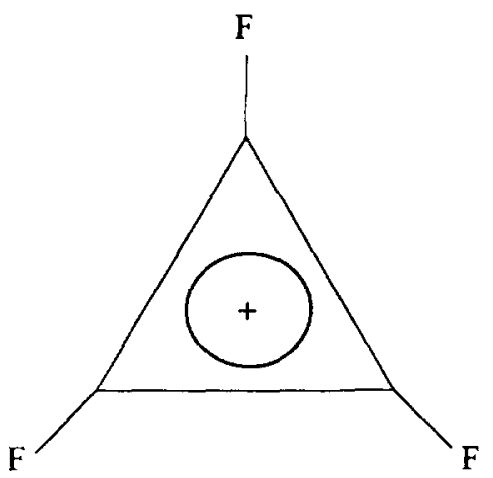

TFCP

\section{${ }^{+} \mathrm{C} \equiv \mathrm{C}-\mathrm{CH}_{3}$}

Fig. 1. Cyclopropenyl (CP), monofluorocyclopropenyl (MFCP), difluorocyclopropenyl (DFCP), trifluorocyclopropenyl (TFCP) and propargyl (P) cations.

orbital to form the $\mathrm{C}-\mathrm{H}$ bond and two $\mathrm{sp}^{3}$ hybrids in the ring plane to form the bent $\mathrm{C}-\mathrm{C} \sigma$ bonds, while the remaining $\mathrm{p}$ orbital participates in the cation $\pi$ system [13]. These conclusions were further supported by theoretical studies [14]. More recently, all the hydrogen-deuterium isotopomers of $\mathbf{C P}$ were prepared and studied by vibrational spectroscopy in both gaseous and condensed phases [15]. The experimental data indicated that both the $f_{\mathrm{CC}}$ and $f_{\mathrm{CH}}$ force constants are larger than those found in benzene, thus pointing to a stronger $\pi$ bond in CP than in benzene.

Several theoretical studies, using different levels of approximation, have also been carried out on 
CP. These include Hartree-Fock SCF calculations (using a minimal basis set [9], gaussian lobe functions [16] or double or triple- $\zeta$ plus polarization functions $[8,10,12,17])$, Møller-Plesset perturbation theory up to fourth order [11,18-20], interaction of configurations $[14,19]$, and approximated coupled cluster methods $[18,19]$. In consonance with the experimental data, all these theoretical methods predict $\mathbf{C P}$ as a planar $D_{3 \mathrm{~h}}$ symmetric cation. In addition, the highest level thcorctical calculations yield $R_{\mathrm{e}}(\mathrm{C}-\mathrm{C})=136.2-137.1 \mathrm{pm}$ and $R_{\mathrm{e}}(\mathrm{C}-\mathrm{H})=107.5-108.3 \mathrm{pm}[11,18-20]$. However, it has been suggested [19] that the $\mathrm{C}-\mathrm{C}$ bond lengths are probably overestimated by the theoretical calculations, whereas the $\mathrm{C}-\mathrm{H}$ distances are slightly underestimated.

Two theoretical studies of the vibrational spectra of $\mathbf{C P}$ and its deuterated isotopomers were also reported [18,19]. These studies considered mainly the effects of the anharmonicity on the vibrational spectra of the molecule, and include the computation of both the harmonic and anharmonic force fields of $\mathbf{C P}$, using post-Hartree-Fock methods. While these sophisticated calculations yielded results which agree very well with the experimental data, their gencralization to more complex systems is as yet prohibitive in terms of computational facilities.

Despite the large number of theoretical studies on CP already published, none has looked at the electronic structure of this ion in great detail.

The three fluorosubstituted derivatives of $\mathbf{C P}$ (mono-, di- and trifluorocyclopropenyl cations abbreviated, MFCP, DFCP and TFCP), including several deuterated species, have been prepared and studied by both Raman (in $\mathrm{SO}_{2}$ solution) and infrared spectroscopy (in matrices) [21-23]. The vibrational data conform to a pattern of strengthening of $\mathrm{C}-\mathrm{C}$ bonds due to fluorine substitution on a contiguous carbon atom and of weakening of the distal bond. In the trifluorosubstituted ion these effects were shown to cancel out [23]. In addition, both MFCP and DFCP were shown to have $C_{2 v}$ symmetry, while TFCP, like CP, belongs to the $D_{3 \mathrm{~h}}$ point group.

The fluorosubstituted cyclopropenyl ions have been little studied theoretically. In fact, to the best of our knowledge, only two papers on this subject were published. In the first [12], the equilibrium geometry and charge density distribution (Mulliken population analysis) of MFCP were calculated using a $6-31 G^{*}$ basis set. By comparing the results obtained for MFCP with those found for other monosubstituted cyclopropenyl ions, it was pointed out that fluorine appears to be the unique substituent that leads to the vicinal $\mathrm{C}-\mathrm{C}$ bonds being longer than the distal one. In addition, it was proposed that the $\sigma$-withdrawing ability of the fluorine substituent should be more important than its $\pi$-donation ability. The second study [24] looked at TFCP at the SCF 3-21G and 6-31G* levels of calculation. Optimized geometries using both basis sets and the 3-21G Mulliken population analysis were reported, and the observed increase in the $\mathrm{C}-\mathrm{C}$ bond lengths, when compared to those of $\mathbf{C P}$, was also tentatively interpreted in terms of the $\sigma$-withdrawing and $\pi$ donation effects of the fluorine substituents. None of these calculations included diffuse functions within the basis set, despite the fact that it is well known that these are essential to adequately describe the electronic structure of strongly electronegative atoms [25].

In this paper we present the results of ab initio SCF-MO calculations on both the electronic structure and vibrational spectra of $\mathbf{C P}$ and its fluoroderivatives. In order to properly describe the electron distribution in these ions, the best combination of diffuse and polarization functions to be used, together with the $6-311 \mathrm{G}$ basis set, is first selected. To this end, in the first part of this paper, a very simple and unambiguous criterion for making the composition of the basis set (that may in principle be used successfully when substituents other than fluorine are considered) is presented. In the second part of this paper, the electronic structures of the cations are analysed in detail. Particular emphasis is given to the analysis of the electronic effects due to successive hydrogenby-fluorine replacements. Finally, we present the results of vibrational calculations. Normal mode analysis arc carricd out for all hydrogen-deuterium isotopomers of the studied ions using the ab initio optimized geometries and force fields, and the results compared with the experimental data. The theoretical results are used both to review some band assignments previously proposed for the fluorosubstituted molecules and to give a stronger 
theoretical foundation to the general interpretation of the vibrational spectra of these compounds.

\section{Methods}

Hartree-Fock SCF-MO calculations were carried out on a VAX (model 8820 or 6620) computer using the GAUSSIAN 90 system of programs [26]. Fully optimized gcometries, constrained to the molecular point group, were determined for the studied molecules using the $6-311 \mathrm{G}$ basis set [27] without or with the systematic addition of polarization and/or diffuse functions [25] in "heavy atoms" $(\mathrm{C}, \mathrm{F})$ and $\mathrm{H}$, covering all possible combinations (nine basis sets for CP, MFCP and DFCP, and four basis sets for TFCP). Vibrational frequencies were calculated analytically for all these basis sets to test the rank of the critical points, confirming that all optimized geometries correspond to minima in the potential energy hypersurface. Both the equilibrium geometries and vibrational frequencies were calculated using the default procedures of the program [26].

The force constants (symmetry internal coordinates) to be used in the normal coordinate analysis were obtained from the ab initio cartesian harmonic force constants using the program TRANSFORMER [28]. This program was also used to prepare the input data for the normal coordinate analysis programs used in this study (BUILD-G and VIBRAT [29]). The calculated force fields were scaled down by using a simple linear regression in order to adjust the calculated frequencies of the nine molecules studied (four isotopomers of CP, two of MFCP and DFCP, and one of TFCP) to the observed frequencies. Frequencies corresponding to unobserved or doubtfully assigned vibrations were then calculated from the ab initio force fields by interpolation using the straight line obtained previously. While very simple, this scaling procedure has the advantage, over the more elaborate force field scaling procedures which use several scale factors, of preserving the potential energy distributions (PEDs) as they emerge from the $a b$ initio calculations. In addition, this method can also be used as a simple additional test of the quality of the electron distribution obtained with the basis set used to perform the MO calculations.

\section{Results and discussion}

\subsection{Influence of the polarization and diffuse functions on the calculated electronic structures}

Table 1 presents the calculated bond distances for CP. The largest changes in the calculated values due to the inclusion of polarization/diffuse functions in the basis set occur when the first polarization function (on the carbon atoms) is added: the $\mathrm{C}-\mathrm{C}$ bond lengths become shorter, while the $\mathrm{C}-\mathrm{H}$ bond lengths increase. The inclusion of both the second polarization (on the $\mathbf{H}$ atoms) and/or diffuse functions does not affect significantly the calculated geometry. It is interesting to note that this result agrees with previous studies, suggesting that the most important factors that affect the bond lengths calculated with a given basis set are (i) the presence (or absence) of polarization functions in non-hydrogen atoms and (ii) electron correlation $[11,18,19]$. Indeed, the bond lengths now obtained are shorter than those previously determined using methods that include electron correlation (C-C: $136.2-137.1 \mathrm{pm} ; \quad \mathrm{C}-\mathrm{H}: \quad 107.5-108.3 \mathrm{pm}$ [11,18-20]). Table 1 also shows that the inclusion of polarization functions on the carbon atoms leads to shorter $\mathrm{C} \cdots \mathrm{H}$ non-bonded distances, while the $\mathrm{H} \cdots \mathrm{H}$ non-bonded distances remain

Table 1

Basis set dependence of the calculated bond lengths and distances between non-bonded atoms (pm) of $\mathbf{C P}$

\begin{tabular}{lllll}
\hline Basis $^{\mathrm{a}}$ & $\mathrm{C}-\mathrm{H}$ & $\mathrm{C}-\mathrm{C}$ & $\mathrm{C} \cdots \mathrm{H}$ & $\mathrm{H} \cdots \mathrm{H}$ \\
\hline $\mathrm{G}$ & 106.4 & 136.2 & 234.4 & 320.5 \\
$+\mathrm{G}$ & 106.5 & 136.2 & 234.5 & 320.6 \\
$++\mathrm{G}$ & 106.5 & 136.2 & 234.5 & 320.6 \\
$\mathrm{G}^{*}$ & 107.1 & 135.0 & 234.0 & 320.5 \\
$+\mathrm{G}^{*}$ & 107.1 & 135.0 & 234.0 & 320.5 \\
$++\mathrm{G}^{*}$ & 107.1 & 135.0 & 234.0 & 320.6 \\
$\mathrm{G}^{* *}$ & 107.2 & 135.0 & 234.0 & 320.6 \\
$+\mathrm{G}^{* *}$ & 107.2 & 134.9 & 234.0 & 320.6 \\
$++\mathrm{G}^{* *}$ & 107.1 & 135.0 & 234.0 & 320.6 \\
\hline
\end{tabular}

${ }^{a}$ Abbreviated. $+G^{*}$ represents the $6-311+G^{*}$ basis set. 
Table 2

Basis set dependence of the calculated bond lengths (pm) of MFCP, DFCP and TFCP

\begin{tabular}{|c|c|c|c|c|c|c|c|c|c|c|}
\hline \multirow[t]{2}{*}{ Basis } & \multicolumn{4}{|c|}{ MFCP } & \multicolumn{4}{|l|}{ DFCP } & \multicolumn{2}{|l|}{ TFCP } \\
\hline & $\mathrm{C}-\mathrm{F}$ & $\mathrm{C}-\mathrm{H}$ & $\mathrm{C}(\mathrm{F})-\mathrm{C}(\mathrm{H})$ & $\mathrm{C}(\mathrm{H})-\mathrm{C}(\mathrm{H})$ & $\mathrm{C}-\mathrm{F}$ & $\mathbf{C}-\mathbf{H}$ & $\mathrm{C}(\mathrm{F})-\mathrm{C}(\mathrm{H})$ & $\mathrm{C}(\mathrm{F})-\mathrm{C}(\mathrm{F})$ & $\mathrm{C}-\mathrm{F}$ & $\mathrm{C}-\mathrm{C}$ \\
\hline $\mathrm{G}$ & 128.8 & 106.5 & 135.0 & 137.5 & 128.4 & 106.7 & 136.2 & 134.5 & 128.1 & 135.6 \\
\hline$+G$ & 128.6 & 106.6 & 135.0 & 137.5 & 128.2 & 106.7 & 136.3 & 134.6 & 127.8 & 135.8 \\
\hline$++\mathrm{G}$ & 128.6 & 106.6 & 135.1 & 137.5 & 128.2 & 106.7 & 136.3 & 134.6 & & \\
\hline $\mathrm{G}^{*}$ & 124.1 & 107.2 & 134.4 & 136.3 & 123.9 & 107.3 & 135.6 & 134.4 & 123.7 & 135.6 \\
\hline$+G^{*}$ & 124.1 & 107.2 & 134.3 & 136.3 & 123.8 & 107,3 & 135.6 & 134.4 & 123.6 & 135.6 \\
\hline$++G^{*}$ & 124.1 & 107.3 & 134.3 & 136.3 & 123.8 & 107.3 & 135.6 & 134.4 & & \\
\hline$G^{* *}$ & 124.1 & 107.3 & 134.3 & 136.3 & 123.9 & 107.5 & 135.6 & 134.3 & & \\
\hline$+\mathrm{G}^{* *}$ & 124.1 & 107.3 & 134.3 & 136.3 & 123.8 & 107.4 & 135.6 & 134.4 & & \\
\hline$++\mathrm{G}^{* *}$ & 124.1 & 107.3 & 134.3 & 136.3 & 123.8 & 107.4 & 135.6 & 134.4 & & \\
\hline
\end{tabular}

Abbreviated. $+G^{*}$ represents the $6311+G^{*}$ basis set.

constant upon inclusion of either diffuse or polarization functions.

Table 2 shows the calculated bond distances for the fluorosubstituted cyclopropenyl ions. The general pattern of variation with the basis set is similar to that observed for CP. The inclusion of polarization functions makes the "heavy atom-heavy atom" ( $\mathrm{C}-\mathrm{F}$ and $\mathrm{C}-\mathrm{C}$ ) bond lengths shorter and the $\mathrm{C}-\mathrm{H}$ bond lengths longer. The inclusion of diffuse functions gives rise to very small (less than $0.3 \mathrm{pm}$ ) and non-systematic changes in bond lengths.

For symmetry reasons, the bond angles of both CP and TFCP do not depend on the basis set. In turn, the calculated changes in the bond angles of MFCP and DFCP due to the addition of polarization or diffuse functions to the basis set do not exceed $1^{\circ}$.

Table 3 shows the dependence on the basis set of both the total energies and heats of formation calculated with or without including zero-point energy corrections. From these data, it can be concluded that the basis set dependence of the calculated energies conform to a pattern similar to that followed by their geometries (Tables 1 and 2). In particular, the inclusion of the first polarization function produces the largest changes. Hence, both energetic and geometric results clearly indicate that the addition of polarization functions on the non-hydrogen atoms to the 6-311G basis set is required to improve the performance. However, in order to evaluate the general quality of a given basis set, a systematic analysis of the electron distribution it yields is crucial.
Table 4 presents the gross $\left(\chi_{\mathrm{g}}\right)$ and the net $\left(\chi_{\mathrm{n}}\right)$ Mulliken atomic electron populations for $\mathbf{C P}$ calculated with the various basis sets used. The gross charges on the carbon atoms $\left(q(\mathrm{c})=6-\chi_{\mathrm{g}}\right)$ are near zero for the $6-311 \mathrm{G}$ basis set. The addition of a diffuse function on these atoms increases their gross electron population. A further increase is observed upon the addition of the second diffuse function (on the hydrogen atoms). On the contrary, the addition of the first polarization function (on the carbon atoms) to the basis set produces only a very small increase in the carbon gross electron population, whereas the addition of the second one (on the hydrogen atoms) makes the gross charge of the carbon atoms slightly positive. The net charges on the carbon atoms present a quite different pattern. Thus, the addition of polarization functions (either on the carbon or on the hydrogen atoms) leads to an electron charge transfer from the carbon atoms to both the overlap terms $\left(\chi_{0}(\mathrm{C}-\mathrm{C})\right.$ and $\left.\chi_{0}(\mathrm{C}-\mathrm{H})\right)$ and hydrogen atoms; the addition of the first diffuse function produces a decrease in the net electron population of the carbon atoms, whereas the addition of the second one increases the net electron population of these atoms to a higher value than the initial one.

Table 4 also presents the total $\mathrm{C}-\mathrm{C}$ and $\mathrm{C}-\mathrm{H}$ overlap populations. It is important to note that several basis sets represent the $\mathrm{C}-\mathrm{C}$ bonds as having a smaller (or nearly equal) overlap population than the $\mathrm{C}-\mathrm{H}$ bonds. Obviously, this result is not reasonable, since the $\mathrm{C}-\mathrm{C}$ bonds are known to 


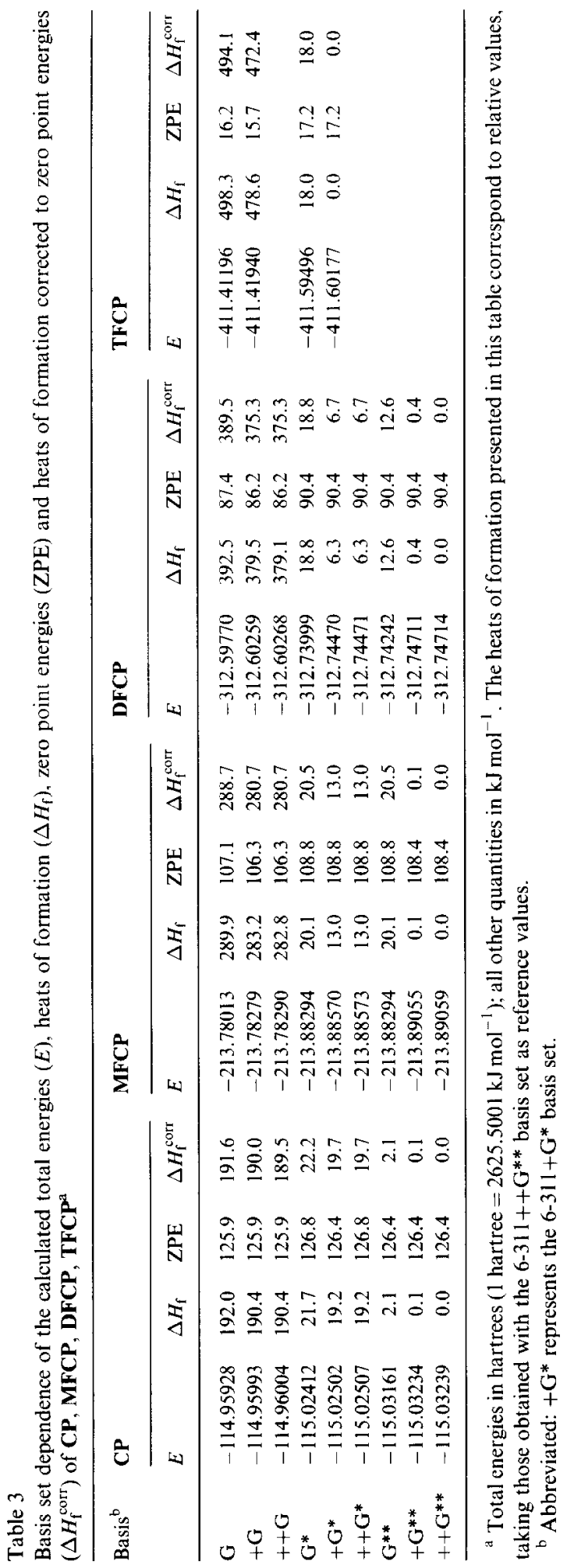


lable 4

Basis set dependence of the calculated gross $\left(\chi_{g}\right)$ and net $\left(\chi_{\mathbf{n}}\right)$ Mulliken atomic populations and overlap ( $\left.\chi_{\mathrm{o}}\right)$ populations of $\mathbf{C P}^{\mathrm{a}}$

\begin{tabular}{lcccccccccccc}
\hline Basis $^{\mathrm{b}}$ & $\chi_{\mathrm{g}}(\mathrm{C})$ & $\sigma_{\mathrm{g}}(\mathrm{C})$ & $\pi_{\mathrm{g}}(\mathrm{C})$ & $\chi_{\mathrm{g}}(\mathrm{H})$ & $\chi_{\mathbf{n}}(\mathrm{C})$ & $\sigma_{\mathrm{n}}(\mathrm{C})$ & $\pi_{\mathrm{n}}(\mathrm{C})$ & $\chi_{\mathrm{n}}(\mathrm{H})$ & $\chi_{\mathrm{O}}(\mathrm{C}-\mathrm{C})$ & $\sigma_{\mathrm{O}}(\mathrm{C}-\mathrm{C})$ & $\pi_{\mathrm{O}}(\mathrm{C}-\mathrm{C})$ & $\chi_{\mathrm{O}}(\mathrm{C}-\mathrm{H})$ \\
\hline $\mathrm{G}$ & 6.008 & 5.341 & 0.667 & 0.659 & 5.433 & 5.110 & 0.323 & 0.315 & 0.116 & -0.004 & 0.120 & 0.353 \\
$+\mathrm{G}$ & 6.047 & 5.380 & 0.667 & 0.620 & 5.079 & 4.755 & 0.324 & 0.291 & 0.320 & 0.201 & 0.120 & 0.346 \\
$++\mathrm{G}$ & 6.119 & 5.452 & 0.667 & 0.549 & 5.595 & 5.271 & 0.324 & 0.293 & 0.132 & 0.013 & 0.120 & 0.383 \\
$\mathrm{G}^{*}$ & 6.014 & 5.347 & 0.667 & 0.653 & 5.052 & 4.752 & 0.301 & 0.308 & 0.308 & 0.177 & 0.132 & 0.366 \\
$+\mathrm{G}^{*}$ & 6.032 & 5.389 & 0.643 & 0.634 & 4.783 & 4.481 & 0.301 & 0.293 & 0.454 & 0.323 & 0.132 & 0.310 \\
$++\mathrm{G}^{*}$ & 6.074 & 5.407 & 0.667 & 0.593 & 5.289 & 4.988 & 0.301 & 0.280 & 0.237 & 0.105 & 0.132 & 0.332 \\
$\mathrm{G}^{* *}$ & 5.889 & 5.225 & 0.664 & 0.778 & 4.992 & 4.695 & 0.297 & 0.392 & 0.255 & 0.124 & 0.132 & 0.415 \\
$+\mathrm{G}^{* *}$ & 5.913 & 5.249 & 0.664 & 0.754 & 4.633 & 4.485 & 0.298 & 0.369 & 0.447 & 0.316 & 0.131 & 0.369 \\
$++\mathrm{G}^{* *}$ & 5.967 & 5.303 & 0.664 & 0.700 & 4.888 & 4.590 & 0.298 & 0.336 & 0.358 & 0.227 & 0.131 & 0.348 \\
\hline
\end{tabular}

${ }^{2}$ In units of $e\left(e=1.60219 \times 10^{-19} \mathrm{C}\right) ; \pi_{\mathrm{g}}(\mathrm{H}), \pi_{\mathrm{n}}(\mathrm{H})$ and $\pi_{\mathrm{O}}(\mathrm{C}-\mathrm{H})$ are not presented as they have been found to be negligible.

${ }^{b}$ Abbreviated. $+\mathrm{G}^{*}$ represents the $6-311+\mathrm{G}^{*}$ basis set.

have a considerable double bond character. From this point of view, only the $6-311+\mathrm{G}^{*}$ and 6-311+G** basis sets can be considered to yield proper results, pointing to the relevance of the presence of a diffuse function on the carbon atoms, in addition to the polarization function.

From the analysis of the $\pi$ and $\sigma$ gross, net and overlap populations calculated for CP (Table 4), it can be concluded that:

(i) The $\pi$ gross and net electron populations do not change very much with the addition of either diffuse or polarization functions. This result indicates that both polarization and diffuse functions are more important to the description of the $\sigma$ system than to the description of the $\pi$ system. In fact, the changes in the total atomic populations with the addition of these functions to the basis set are essentially equal to those observed in the $\sigma$ populations.

(ii) The $\sigma / \pi$ partition of the $\mathrm{C}-\mathrm{C}$ overlap populations yields very interesting results. For instance, the 6-311G basis set fails to account for a $\mathrm{C}-\mathrm{C} \sigma$ bond. In addition, several other basis sets herein studied yield a $\mathrm{C}-\mathrm{C} \pi$ overlap population, $\pi_{\mathrm{O}}(\mathrm{C}-\mathrm{C})$, greater than or equal to the $\sigma$ one, $\sigma_{\mathrm{O}}(\mathrm{C}-\mathrm{C})$. Indeed, only two basis sets among the whole set considered $\left(6-311+\mathrm{G}^{*}\right.$ and $\left.6-311+\mathrm{G}^{* *}\right)$ do not fail to predict properly the ratio $\pi_{\mathrm{O}}(\mathrm{C}-\mathrm{C}) / \sigma_{\mathrm{O}}(\mathrm{C}-$ C) which, considering the $\pi$-bond order of a $\mathrm{C}-\mathrm{C}$ symmetrically delocalized partial double bond in a three-membered cyclic molecule, must be close to 0.33 .

Table 5 presents both $\mathrm{C}-\mathrm{C}$ and $\mathrm{C}-\mathrm{F} \sigma$ and $\pi$ overlap populations for DFCP. It can be concluded from this table and from similar data

Table 5

Basis set dependence of the calculated overlap populatins between "heavy atoms" of DFCP

\begin{tabular}{llllllr}
\hline Basis $^{b}$ & $\pi_{\mathrm{O}}(\mathrm{C}-\mathrm{F})$ & $\sigma_{\mathrm{O}}(\mathrm{C}-\mathrm{F})$ & $\pi_{\mathrm{O}}(\mathrm{C}(\mathrm{H})-\mathrm{C}(\mathrm{F}))$ & $\sigma_{\mathrm{O}}(\mathrm{C}(\mathrm{H})-\mathrm{C}(\mathrm{F}))$ & $\pi_{\mathrm{O}}(\mathrm{C}(\mathrm{F})-\mathrm{C}(\mathrm{F}))$ & $\sigma_{\mathrm{O}}(\mathrm{C}(\mathrm{F})-\mathrm{C}(\mathrm{F}))$ \\
\hline $\mathrm{G}$ & 0.028 & 0.207 & 0.119 & -0.258 & 0.107 & -0.124 \\
$+\mathrm{G}$ & 0.028 & 0.212 & 0.119 & -0.269 & 0.108 & -0.239 \\
$++\mathrm{G}$ & 0.028 & 0.235 & 0.119 & -0.714 & 0.109 & 0.128 \\
$\mathrm{G}^{*}$ & 0.067 & 0.277 & 0.136 & -0.017 & 0.120 & 0.138 \\
$+\mathrm{G}^{*}$ & 0.059 & 0.133 & 0.138 & 0.255 & 0.130 & 0.177 \\
$++\mathrm{G}^{*}$ & 0.059 & 0.146 & 0.138 & -0.125 & 0.113 & 0.131 \\
$\mathrm{G}^{* *}$ & 0.067 & 0.276 & 0.135 & 0.222 & 0.129 & 0.128 \\
$+\mathrm{G}^{* *}$ & 0.058 & 0.127 & 0.137 & 0.140 & 0.210 \\
$+\mathrm{G}^{* *}$ & 0.058 & 0.139 & 0.137 & & & 0.130 \\
\hline
\end{tabular}

${ }^{a}$ In units of $e\left(e=1.60219 \times 10^{-19} \mathrm{C}\right)$.

${ }^{b}$ Abbreviated. $+\mathrm{G}^{*}$ represents the $6-311+\mathrm{G}^{*}$ basis set. 
obtained for MFCP and TFCP (not shown here in the interest of brevity; complete results are available from the authors) that the inclusion of polarization functions on non-hydrogen atoms (carbon, fluorine) produces large changes in the calculated $\pi$ overlap populations, whereas the presence of polarization functions on hydrogen atoms does not significantly affect these populations. In turn, the addition of diffuse functions to the $6-311 \mathrm{G}$ basis set without polarization functions does not affect $\pi$ overlap populations, whereas the inclusion of diffuse functions to the $6-311 \mathrm{G}^{*}$ or $6-311 \mathrm{G}^{* *}$ basis produces small changes on both $\mathrm{C}-\mathrm{F}$ and $\mathrm{C}(\mathrm{H})-\mathrm{C}(\mathrm{F}) \pi$ overlap populations. On the contrary, the $\mathrm{C}(\mathrm{F})-\mathrm{C}(\mathrm{F}) \pi$ overlap is much more sensitive to the addition of diffuse functions to the basis sets which also have polarization functions, though a systematic trend of variation cannot be established. The $\sigma$ overlap populations are much more sensitive to the basis set than the $\pi$ ones. Thus, the first polarization function (on carbon and fluorine atoms) gives rise to a general increase of the $\sigma$ overlap populations, while the second (on hydrogen atoms) has a small effect in the opposite direction. In turn, the single addition of diffuse functions to the 6-311G basis set increases the $\mathrm{C}-\mathrm{F}$ and decreases the $\mathrm{C}(\mathrm{H})-\mathrm{C}(\mathrm{F}) \sigma$ overlap populations, also affecting significantly the $\mathrm{C}(\mathrm{F})-\mathrm{C}(\mathrm{F}) \sigma$ overlap population, although in a non-systematic way. A non-systematic pattern of variation of $\sigma$ populations also occurs when diffuse functions are successively added to those basis sets which have polarization functions.

It is particularly interesting that the results presented in Table 5 show that all basis sets predict that the $\mathrm{C}-\mathrm{F} \pi$ overlap is smaller than $\mathrm{C}-\mathrm{F} \sigma$, which is in consonance with the well-known small $\pi$ donation ability usually exhibited by the fluorine atoms. In addition, it can also be noted that when the basis set does not include at least one diffuse and one polarization function, the calculated $\mathrm{C}-\mathrm{C}$ $\sigma$ overlap populations present negative values. Thus, only four basis sets among the whole set of basis studied do not present this failure: $6-311+\mathrm{G}^{*}$, $6-311++\mathrm{G}^{*}, 6-311+\mathrm{G}^{* *}$ and $6-311++\mathrm{G}^{* *}$. However, both the $6-311++\mathrm{G}^{*}$ and $6-311++\mathrm{G}^{* *}$ basis sets yield $\pi_{\mathrm{O}}(\mathrm{C}(\mathrm{H})-\mathrm{C}(\mathrm{F})) / \sigma_{\mathrm{O}}(\mathrm{C}(\mathrm{H})-\mathrm{C}(\mathrm{F}))$ ratios close to one, while $6-311+\mathrm{G}^{* *}$ yields the $\pi_{\mathrm{O}}(\mathrm{C}(\mathrm{F})-\mathrm{C}(\mathrm{F})) / \sigma_{\mathrm{O}}(\mathrm{C}(\mathrm{F})-\mathrm{C}(\mathrm{F}))$ ratio equal to one, thus predicting $\mathrm{C}-\mathrm{C}$ bonds with a double bond character too large for a conjugated system. Thus, also in the case of the fluorosubstituted cyclopropenyl ions, the population analysis results indicate that, among the whole set of basis studied, the $6-311+\mathrm{G}^{*}$ basis is that which yields the best representation of the electron distribution. In fact, the two above-mentioned ratios exhibit reasonable values when calculated using this basis set $\left(\pi_{\mathrm{O}}(\mathrm{C}(\mathrm{H}) \mathrm{C}(\mathrm{F})) / \sigma_{\mathrm{O}}(\mathrm{C}(\mathrm{H}) \mathrm{C}(\mathrm{F}))=0.62\right.$; $\left.\pi_{\mathrm{O}}(\mathrm{C}(\mathrm{F})-\mathrm{C}(\mathrm{F})) \sigma_{\mathrm{O}}(\mathrm{C}(\mathrm{F})-\mathrm{C}(\mathrm{F}))=0.71\right)$.

In summary, Mulliken population analysis results provide evidence that both polarization and diffuse functions on carbon and fluorine atoms must be added to the $6-311 \mathrm{G}$ basis set in order to reach an adequate description of the electronic density of the molecules studied. In turn, the additional presence of diffuse or polarization functions on hydrogen atoms does not improve the results, and may even make them worse. Indeed, it must be stressed that these results further reinforce the conclusions of previous studies undertaken on different molecules [25,30,31] which pointed out the necessity of including diffuse functions to adequately describe the electron density of molecules having strongly electronegative atoms, in particular when the 6-311G basis set is used.

It has been pointed out frequently that Mulliken charges are quite sensitive to changes in the basis set and usually do not converge to a given value upon increasing the basis set size [32]. On the contrary, the charges obtained using the charge-charge flux-overlap (CCFO) model [33] present very good stability with respect to changes in the basis set, since in general this model is able to represent properly the electron distribution of a given molecule [34]. Thus, we have decided to test the reliability of the method presented above to choose the best basis set by also looking at the basis set dependence of the charges obtained from the CCFO model.

In Table 6 the CCFO derived atomic charges $\left(q^{c}\right)$ for $\mathbf{C P}$ are compared with those obtained from the Mulliken partition analysis ( $q^{\mathrm{M}}$; see also Table 4$)$. From this table it can be concluded that for this molecule the addition of a polarization function to the 6-311G basis set increases the positive charge of the carbon atoms and reduces that of the hydrogens, while the addition of the second set of polarization 
Table 6

Basis set dependence of the atomic charges of $\mathbf{C P}$ calculated using the Mulliken atomic partition criterion $\left(q^{\mathrm{M}}\right)$ and the CCFO model $\left(q^{c}\right)^{\mathrm{a}}$

\begin{tabular}{lllll}
\hline Basis $^{\mathrm{h}}$ & $q^{\mathrm{c}}(\mathrm{C})$ & $q^{\mathrm{M}}(\mathrm{C})$ & $q^{\mathrm{c}}(\mathrm{H})$ & $q^{\mathrm{M}}(\mathrm{H})$ \\
\hline $\mathrm{G}$ & 0.098 & -0.008 & 0.235 & 0.341 \\
$+\mathrm{G}$ & 0.095 & -0.047 & 0.238 & 0.380 \\
$++\mathrm{G}$ & 0.098 & -0.119 & 0.235 & 0.452 \\
$\mathrm{G}^{*}$ & 0.148 & -0.014 & 0.185 & 0.347 \\
$+\mathrm{G}^{*}$ & 0.148 & -0.032 & 0.185 & 0.366 \\
$++\mathrm{G}^{*}$ & 0.149 & -0.074 & 0.185 & 0.407 \\
$\mathrm{G}^{* *}$ & 0.146 & 0.111 & 0.188 & 0.222 \\
$+\mathrm{G}^{* *}$ & 0.147 & 0.087 & 0.185 & 0.245 \\
$++\mathrm{G}^{* *}$ & 0.146 & 0.033 & 0.187 & 0.300 \\
\hline
\end{tabular}

a In units of $e\left(e=1.60219 \times 10^{-14} \mathrm{C}\right)$.

${ }^{b}$ Abbreviated. $+\mathrm{G}^{*}$ represents the $6-311+\mathrm{G}^{*}$ basis set. functions or diffuse functions does not produce any significant change in the CCFO charges.

It is interesting to note that the Mulliken charges do not exhibit a similar behavior, but both the calculated net atomic populations on the carbon atoms and the $\mathrm{C}-\mathrm{C}$ overlap populations (see Table 4) are consistent with the CCFO derived atomic charges. In particular, as was already referred to, the results obtained for these two propertics indicate that the addition of the first set of polarization functions leads to an electron density transfer from the carbon atoms to both the $\mathrm{C}-\mathrm{C}$ overlap and hydrogens. Thus, the changes observed in the CCFO charges may be correlated with those observed for $\mathrm{C}-\mathrm{C}$ bond lengths (a decrease in this bond length is observed upon inclusion of the first set of polarization functions - see Table 1).

Table 7

Basis set dependence of the atomic charges of MFCP, DFCP and TFCP calculated using the Mulliken atomic partition criterion ( $q^{\mathrm{M}}$ ) and the CCFO model $\left(q^{\mathrm{c}}\right)^{\mathrm{a}}$

\begin{tabular}{|c|c|c|c|c|c|c|c|c|}
\hline Basis $^{b}$ & $q^{\mathrm{c}}(\mathrm{C}(\mathrm{H}))$ & $q^{\mathrm{M}}(\mathrm{C}(\mathrm{H}))$ & $q^{c}(\mathrm{C}(\mathrm{F}))$ & $q^{\mathrm{M}}(\mathrm{C}(\mathrm{F}))$ & $q^{c}(\mathbf{H})$ & $q^{\mathrm{M}}(\mathrm{H})$ & $q^{c}(\mathrm{~F})$ & $q^{\mathrm{M}}(\mathrm{F})$ \\
\hline \multicolumn{9}{|l|}{$M F C P$} \\
\hline $\mathrm{G}$ & 0.060 & 0.047 & 0.480 & 0.403 & 0.257 & 0.359 & -0.114 & -0.215 \\
\hline$+\mathrm{G}$ & 0.075 & 0.183 & 0.447 & 0.115 & 0.252 & 0.400 & -0.103 & -0.283 \\
\hline$++\mathrm{G}$ & 0.079 & 0.248 & 0.443 & -0.267 & 0.202 & 0.482 & -0.074 & -0.192 \\
\hline $\mathrm{G}^{*}$ & 0.099 & 0.023 & 0.466 & 0.428 & 0.206 & 0.356 & -0.077 & -0.095 \\
\hline$+G^{*}$ & 0.112 & 0.085 & 0.445 & 0.191 & 0.202 & 0.380 & -0.077 & -0.121 \\
\hline$++G^{*}$ & 0.113 & 0.080 & 0.443 & 0.119 & 0.202 & 0.418 & -0.074 & -0.116 \\
\hline $\mathrm{G}^{* *}$ & 0.100 & 0.106 & 0.463 & 0.420 & 0.206 & 0.230 & -0.076 & -0.091 \\
\hline$+G^{* *}$ & 0.116 & 0.172 & 0.437 & 0.269 & 0.202 & 0.254 & -0.072 & -0.122 \\
\hline$++G^{* *}$ & 0.117 & 0.186 & 0.435 & 0.127 & 0.202 & 0.309 & -0.071 & -0.116 \\
\hline \multicolumn{9}{|l|}{$D F C P$} \\
\hline G & 0.017 & 0.105 & 0.444 & 0.460 & 0.283 & 0.376 & -0.091 & -0.200 \\
\hline$+\mathrm{G}$ & 0.044 & 0.340 & 0.425 & 0.410 & 0.272 & 0.418 & -0.083 & -0.289 \\
\hline$++\mathrm{G}$ & 0.048 & 0.474 & 0.424 & 0.281 & 0.270 & 0.518 & -0.083 & -0.277 \\
\hline $\mathrm{G}^{*}$ & 0.041 & -0.018 & 0.419 & 0.411 & 0.231 & 0.365 & -0.055 & -0.085 \\
\hline$+\mathrm{G}^{*}$ & 0.069 & 0.184 & 0.407 & 0.340 & 0.223 & 0.390 & -0.053 & -0.127 \\
\hline$++G^{*}$ & 0.071 & 0.314 & 0.406 & 0.252 & 0.223 & 0.429 & -0.053 & -0.123 \\
\hline $\mathrm{G}^{* *}$ & 0.043 & 0.114 & 0.418 & 0.407 & 0.231 & 0.238 & -0.055 & -0.083 \\
\hline$+\mathrm{G}^{* *}$ & 0.075 & 0.227 & 0.404 & 0.383 & 0.221 & 0.262 & -0.052 & -0.127 \\
\hline$++\mathrm{G}^{* *}$ & 0.075 & 0.388 & 0.404 & 0.270 & 0.221 & 0.318 & -0.052 & -0.123 \\
\hline \multicolumn{9}{|l|}{ TFCP } \\
\hline G & & & 0.399 & 0.520 & & & -0.066 & -0.187 \\
\hline$+\mathrm{G}$ & & & 0.393 & 0.619 & & & -0.059 & -0.286 \\
\hline $\mathrm{G}^{*}$ & & & 0.363 & 0.409 & & & -0.030 & -0.076 \\
\hline$+\mathrm{G}^{*}$ & & & 0.362 & 0.460 & & & -0.029 & -0.127 \\
\hline
\end{tabular}

${ }^{a}$ In units of $e\left(e=1.60219 \times 10^{-19} \mathrm{C}\right)$.

${ }^{b}$ Abbreviated. $+G^{*}$ represents the $6-311+^{*}$ basis set. 
Table 7 presents the CCFO and Mulliken atomic charges for the fluorosubstituted cyclopropenyl ions. The additon of both diffuse and polarization functions generally increases $q^{\mathrm{c}}(\mathrm{C}(\mathrm{H}))$ and $q^{\mathrm{c}}(\mathrm{F})$, and decreases $q^{\mathrm{C}}(\mathrm{C}(\mathrm{F}))$ and $q^{\mathrm{c}}(\mathrm{H})$. However, after the addition of the first polarization and diffuse functions (i.e. for the $6-311+\mathrm{G}^{*}$ basis set) all $q^{\mathrm{c}}$ values have already practically converged. Ihus, once again, the $6-311+\mathrm{G}^{*}$ basis set appears as the smallest basis set among those considered which is able to describe well the electronic structure of both CP and its fluoroderivatives.

It is also interesting to note that, as was found for the non-substituted ion, a correlation between the CCFO charges (not the Mulliken ones) and both the Mulliken overlap populations and bond lengths may also be established for the fluorinecontaining compounds. Thus, fluorine atoms lost electronic density to the $\mathrm{C}-\mathrm{F}$ overlap and $\mathrm{C}(\mathrm{F})$ atoms with the increase of the basis set, leading to a less negative charge on the fluorine atoms and to a less positive charge on the $\mathrm{C}(\mathrm{F})$ atoms. In turn, $\mathrm{C}(\mathrm{H})$ transfers electronic density to all overlaps and atoms bonded to this atom (i.e. the Table 8

C C and C F bond lengths (pm) of CP, MFCP, DFCP, TFCP and several related molecules calculated with the $6-311+\mathrm{G}^{*}$ basis set

\begin{tabular}{|c|c|c|c|c|}
\hline Molecule & $\mathrm{C}(\mathrm{H})-\mathrm{C}(\mathrm{H})$ & $\mathrm{C}(\mathrm{H})-\mathrm{C}(\mathrm{F})$ & $C(F)-C(F)$ & $\mathrm{C} \cdots \mathrm{F}$ \\
\hline Ethane & 152.7 & & & \\
\hline Fluoroethane & & 151.1 & & 137.4 \\
\hline Ethylene & 131.9 & & & \\
\hline Fluoroethylene & & 130.9 & & 132.6 \\
\hline Acetylene & 118.3 & & & \\
\hline Fluoroacetylene & & 117.4 & & 126.0 \\
\hline Cyclopropane & 150.1 & & & \\
\hline Fluorocyclopropane & 151.6 & 148.2 & & 125.4 \\
\hline Cyclopropene & $\begin{array}{l}149.9(\mathrm{C}-\mathrm{C}) \\
127.6(\mathrm{C}=\mathrm{C})\end{array}$ & & & \\
\hline 1-Fluorocyclopropene & 154.3 & $\begin{array}{l}146.0 \\
126.5\end{array}$ & & 129.3 \\
\hline 3-Fluorocyclopropene & 128.9 & 145.7 & & 137.4 \\
\hline Allyl cation & 137.3 & & & \\
\hline 1-Fluoroallyl cation & 136.1 & 138.5 & & 125.7 \\
\hline 2-Fluoroallyl cation & & 136.8 & & 130.4 \\
\hline Cyclopropyl cation & $\begin{array}{l}144.0\left(C_{1}-C_{2}\right) \\
151.4\left(C_{2}-C_{3}\right)\end{array}$ & & & \\
\hline 1-Fluorocyclopropyl cation & 156.9 & 142.0 & & 122.0 \\
\hline CP & 135.0 & & & \\
\hline MFCP & 136.3 & 134.3 & & 124.1 \\
\hline DFCP & & 135.6 & 134.4 & 123.8 \\
\hline TFCP & & & 123.6 & 123.6 \\
\hline
\end{tabular}
charge on hydrogen less positive). Finally, a decrease in a given $\mathrm{C}-\mathrm{C}$ or $\mathrm{C}-\mathrm{F}$ bond length correlates with both an increase in the corresponding overlap population and a decrease of the $\mathrm{CCFO}$ charges (absolute values) of the atoms making the bond.

In summary, the analysis of the dependence on the basis set of bond lengths, energies, Mulliken atomic and overlap populations, and CCFO charges calculated for the non-substituted as well as for the various fluorosubstituted cyclopropenyl ions studied clearly indicates that the smallest basis set which yields reliable results for the four molecules considered is the $6-311+G^{*}$. The method used here to choose the basis set is very simple, and is mainly based on a property that is calculated by almost all program packages used to carry out ab initio MO calculations.

\subsection{Effects of fluorine substitution on the electronic structure of $\boldsymbol{C P}$}

Table 8 shows the $6-311+\mathrm{G}^{*}$ calculated $\mathrm{C}-\mathrm{C}$ and $\mathrm{C}-\mathrm{F}$ bond lengths for a series of organic com- charge on $\mathrm{C}(\mathrm{H})$ becomes more positive and the 
pounds and some of their fluorine-substituted derivatives. From this table, the following conclusions can be drawn:

(i) As could be anticipated, the $\mathrm{C}-\mathrm{C}$ bonds in $\mathbf{C P}$ have a considerable double bond character, the $\mathrm{C}-\mathrm{C}$ bond length being in between those found for ethane and ethylene (or in between the single and double bonds of cyclopropene). In addition, the calculations indicate that the $\mathrm{C}-\mathrm{C}$ bond length in $\mathbf{C P}$ has a greater double bond character (i.c. it is shorter) than in the allyl cation. These results agree with a previous experimental study [15], which has suggested that the $\mathrm{C}-\mathrm{C}$ bonds in $\mathrm{CP}$ should be stronger than in benzene.

(ii) As found for other three-membered cyclic compounds [12,35-39], the $\mathrm{H} \rightarrow \mathrm{F}$ substitution leads to a shortening of the vicinal $\mathrm{C}-\mathrm{C}$ bonds and to an increase of the bond length of the distal $\mathrm{C}-\mathrm{C}$ bond. These results are in consonance with a relative decrease in the $\mathrm{p}$ character of the carbon $\mathrm{sp}^{3}$ hybrid orbitals involved in the $\sigma$ vicinal $\mathrm{C}-\mathrm{C}$ bonds. This decrease of $p$ character of the carbon $\mathrm{sp}^{3}$ hybrid orbitals is accompanied by an increase in $p$ character of the carbon sp hybrid orbital used to make the bond with the fluorine atom, a result which agrees with the expected net electron withdrawing ability of the fluorine substituent. Indeed, it is well known that, in general, the amount of $p$ character of a carbon orbital involved in a bond increases with the withdrawing ability of the substituent [40]. Furthermore, this intepretation is reinforced by looking at the calculated relative

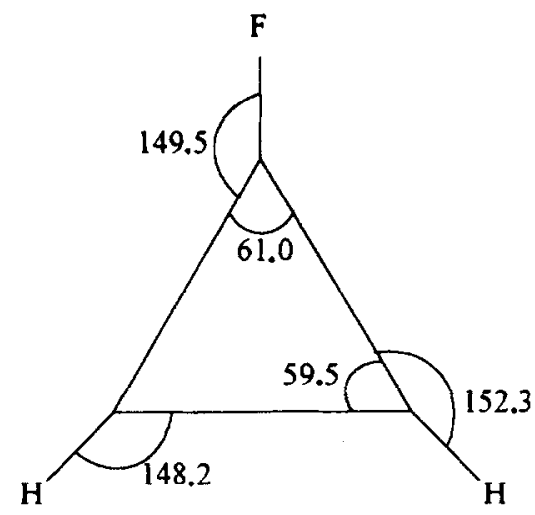

MFCP values of the bond angles around a fluorosubstituted or an unsubstituted carbon atom in the studied ions (Fig. 2). For example, the $\mathrm{C}-\mathrm{C}(\mathrm{F})-\mathrm{C}$ angle is larger than the $\mathrm{C}-\mathrm{C}(\mathrm{H})-\mathrm{C}$ one because the $\mathrm{C}(\mathrm{F})$ atom uses hybrid orbitals with larger $\mathrm{s}$ character to make the $\mathrm{C}-\mathrm{C}$ bonds than the $\mathrm{C}(\mathrm{H})$ atom. In addition, the $\mathrm{F}-\mathrm{C}-\mathrm{C}(\mathrm{F})$ and $\mathrm{H}-\mathrm{C}-\mathrm{C}(\mathrm{F})$ angles are larger than the $\mathrm{F}-\mathrm{C}-\mathrm{C}(\mathrm{H})$ and $\mathrm{H}-\mathrm{C}$ $\mathrm{C}(\mathrm{H})$ angles, respectively, because the central carbon atoms use an hybrid orbital with larger $s$ character to make the $\mathrm{C}-\mathrm{C}(\mathrm{F})$ bond than the $\mathrm{C}-\mathrm{C}(\mathrm{H})$ bond.

(iii) The second $\mathrm{H} \rightarrow \mathrm{F}$ substitution leads to an increase in the $\mathrm{C}(\mathrm{F})-\mathrm{C}(\mathrm{H})$ bond length, while the $\mathrm{C}(\mathrm{F})-\mathrm{C}(\mathrm{F})$ bond length assumes a value nearly equal to that of the $\mathrm{C}(\mathrm{F})-\mathrm{C}(\mathrm{H})$ bond in MFCP. The first observation correlates with a decrease in the $\mathrm{s}$ character of the $\mathrm{sp}^{3}$ hybrids orbitals of the $\mathrm{C}(\mathrm{H})$ atom (this atom is now bonded to two $\mathrm{C}(\mathrm{F})$ atoms, which are more electronegative than a $\mathrm{C}(\mathrm{H})$ atom), while the second one indicates that the hybridization of the $\mathrm{C}(\mathrm{F})$ atom is not significantly affected by the presence of a second fluorine substituent (certainly because opposite effects due to the substitution cancel out to a large extent). This last result agrees with vibrational data $[21,22]$ which have revealed that the force constants associated with the $\mathrm{C}(\mathrm{F})-\mathrm{C}(\mathrm{H})$ bond in MFCP and with the $\mathrm{C}(\mathrm{F})-\mathrm{C}(\mathrm{F})$ bond in DFCP do not differ significantly.

(iv) The calculated changes in bond lengths and angles due to the third $\mathrm{H} \rightarrow \mathrm{F}$ substitution can also be explained considering changes in the relative $s / p$

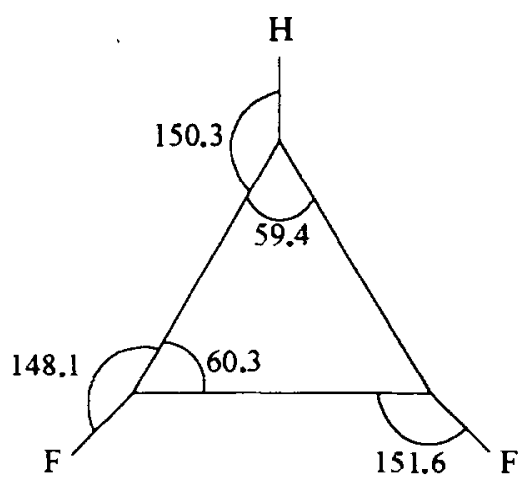

DFCP

Fig. 2. 6-311+G* calculated bond angles (degrees) of MFCP and DFCP. 
Table 9

Mulliken gross populations of CP, MFCP, DFCP and TFCP, calculated with the 6-311+G* basis set ${ }^{\text {a }}$

\begin{tabular}{lllllllllll}
\hline Molecule & $\chi_{\mathrm{g}}(\mathrm{C}(\mathrm{H}))$ & $\pi_{\mathrm{g}}(\mathrm{C}(\mathrm{H}))$ & $\sigma_{\mathrm{g}}(\mathrm{C}(\mathrm{H}))$ & $\chi_{\mathrm{g}}(\mathrm{C}(\mathrm{F}))$ & $\pi_{\mathrm{g}}(\mathrm{C}(\mathrm{F}))$ & $\sigma_{\mathrm{g}}(\mathrm{C}(\mathrm{F}))$ & $\chi_{\mathrm{g}}(\mathrm{F})$ & $\pi_{\mathrm{g}}(\mathrm{F})$ & $\sigma_{\mathrm{g}}(\mathrm{F})$ & $\chi_{\mathrm{g}}(\mathrm{H})$ \\
\hline CP & 6.032 & 0.643 & 5.389 & & & & & & & \\
MFCP & 5.915 & 0.683 & 5.232 & 5.809 & 0.794 & 5.014 & 9.121 & 1.841 & 7.280 & 0.634 \\
DFCP & 5.816 & 0.709 & 5.107 & 5.660 & 0.806 & 4.855 & 9.127 & 1.840 & 7.287 & 0.610 \\
TFCP & & & & 5.540 & 0.827 & 4.713 & 9.127 & 1.840 & 7.287 & \\
\hline
\end{tabular}

${ }^{a}$ In units of $e\left(e=1.60219 \times 10^{-19} \mathrm{C}\right)$.

contributions to the $\sigma$-system hybrid orbitals of the carbon atoms. In particular, the $\mathrm{C}-\mathrm{C}$ bond length increases, due to the decreased $s$ character of the hybrid orbitals of the carbon atoms used to make the $\mathrm{C}-\mathrm{C}$ bonds.

(v) The $\mathrm{C}-\mathrm{F}$ bond lengths decrease slightly with the number of fluorine atoms, showing that the $\mathrm{s}$ character of the carbon orbitals used to make the $\mathrm{C} \mathrm{F}$ bonds increases with the number of fluorine atoms, and thus being in agreement with the above conclusions taken mainly by analysis of the influence of the $\mathrm{H} \rightarrow \mathrm{F}$ substitutions on the $\mathrm{C}-\mathrm{C}$ bond lengths.

(vi) Finally, by comparing the $\mathrm{C}-\mathrm{F}$ bond lengths in the fluorosubstituted cyclopropenyl ions with those obtained for almost all the remaining compounds considered in Table 8 , it can be concluded that in the studied cations this bond is very short. This may be due, at least in part, to an increased double bond character of this bond in the studied ions.

Table 9 presents the Mulliken gross atomic populations and their $\sigma / \pi$ components for the studied ions. The total atomic populations of the carbon atoms, as well as their $\sigma$ components, reduce with the number of fluorine atoms, showing that the fluorine atoms act as $\sigma$ electron withdrawing substituents. As expected, the total atomic population of the $\mathrm{C}(\mathrm{H})$ atoms is always larger than that of the $\mathrm{C}(\mathrm{F})$ atoms and, thus, $\mathrm{C}(\mathrm{H})$ atoms have a smaller positive charge than $C(F)$ atoms. On the contrary, the $\pi$ atomic populations of the carbon atoms increase with the number of fluorine atoms. Thus, it can be concluded that the fluorine substituents act as $\pi$ electron donors. However, the largest changes occur in the $\sigma$ components, clearly showing that the fluorine $\sigma$ electron withdrawing effect is dominant by far. The gross atomic popula- tions of both the hydrogen and fluorine atoms do not change appreciably with substitution. In the case of the hydrogen atoms, this may be easily correlated with the fact that, as hydrogen does not have $\pi$ orbitals easily accessible to make bonds, these atoms are not susceptible of changes in the hybridization state [41]. In turn, the fact that the gross atomic populations of the fluorine atoms (and their $\sigma$ and $\pi$ components) do not change appreciably with substitution indicates that, in the ions, both the $\sigma$ electron withdrawing and $\pi$ electron releasing ability of a fluorine atom are not affected significantly by its chemical environment.

Table 10 shows the Mulliken net atomic popuItions and the overlap populations calculated for the studied ions. The net atomic populations of the carbon atoms increase with the number of fluorine atoms, i.e. they show the opposite behavior to that followed by the corresponding gross atomic populations. In fact, this apparent discrepancy results from the considerable reduction of the $\mathrm{C}-\mathrm{C}$ overlap populations with the number of fluorine atoms (for instance, $\chi_{0} \mathrm{C}(\mathrm{H})-\mathrm{C}(\mathrm{H})$ reduces by about $0.120 e, \chi_{0} \mathrm{C}(\mathrm{F})-\mathrm{C}(\mathrm{H})$ by about $0.080 e$, and $\chi_{0} \mathrm{C}(\mathrm{F})-\mathrm{C}(\mathrm{F})$ by above $\left.0.050 e\right)$. Thus, $\mathrm{H} \rightarrow \mathrm{F}$ substitutions lead to an electron charge transfer from the $\mathrm{C}-\mathrm{C}$ bonds to the carbon atoms. Indeed, this result agrees with the general increase found in the $\mathrm{C}-\mathrm{C}$ bond lengths - either $\mathrm{C}(\mathrm{H})-\mathrm{C}(\mathrm{H}), \mathrm{C}(\mathrm{F})-\mathrm{C}(\mathrm{H})$ or $\mathrm{C}(\mathrm{F})-\mathrm{C}(\mathrm{F})$ - with $\mathrm{H} \rightarrow \mathrm{F}$ substitutions (see Table 8 ), and may be easily understood, considering that progressive substitutions lead to increases in the electronegativity of the carbon atoms. The net atomic populations of the hydrogen atoms decrease slightly with substitution, while the $\mathrm{C}-\mathrm{H}$ overlap populations do not vary. Hence, the calculated changes in the net atomic populations of hydrogen 


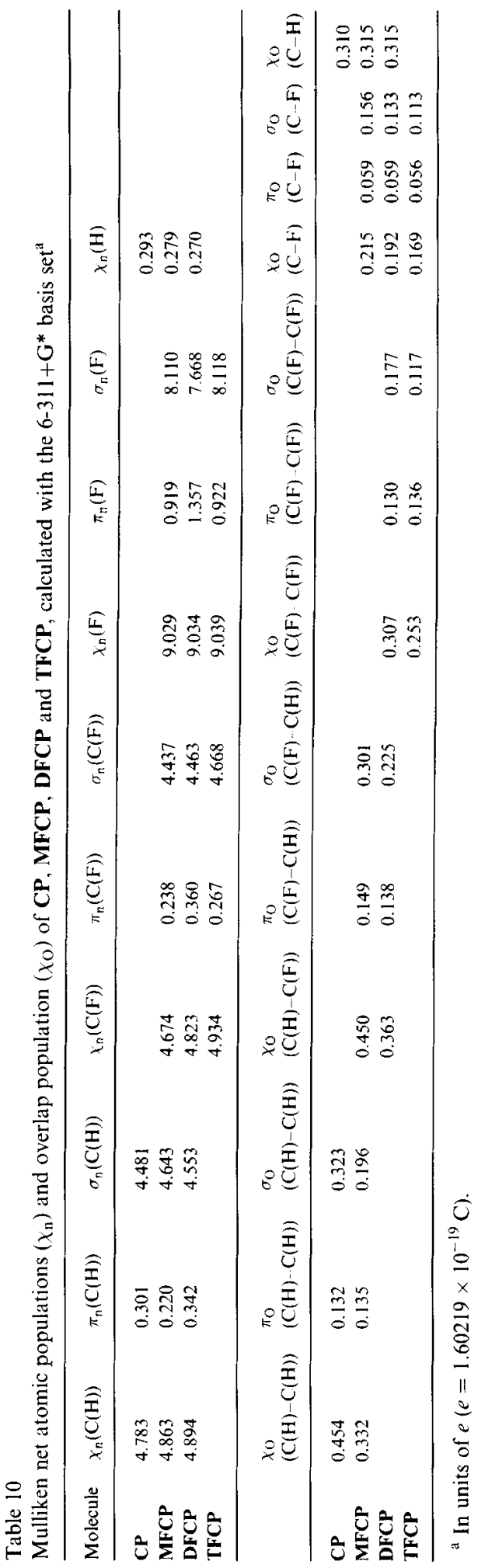


are similar to those found in the gross atomic populations. Finally, both the net atomic populations of the fluorine atom and the $\mathrm{C}-\mathrm{F}$ overlap populations do not change appreciably with the number of $\mathrm{H} \rightarrow \mathrm{F}$ substitutions, thus reinforcing our previous conclusion that, in these ions the electronic effects due to a fluorine atom are essentially equal and independent of the number of fluorine substituents.

From the analysis of the $\pi / \sigma$ partitioning of the net atomic populations and of the overlap populations, also shown in Table 10, the following conclusions can be drawn:

(i) The $\pi \mathrm{C}-\mathrm{C}$ (either $\mathrm{C}(\mathrm{H})-\mathrm{C}(\mathrm{H}), \mathrm{C}(\mathrm{F})-\mathrm{C}(\mathrm{H})$, or $C(F)-C(F)$ ) overlap populations do not change appreciably with the $\mathrm{H} \rightarrow \mathrm{F}$ substitutions. In addition, they do not correlate with the $\mathrm{C}-\mathrm{C}$ bond lengths. This result is particularly interesting, as it shows that mesomerism does not play an important role in determining the relative values of the $\mathrm{C}-\mathrm{C}$ bond lengths in the series of ions studied. Consequently, an explanation of the geometries of MFCP and DFCP in terms of dominant contributions of the resonance structures shown below is not supported by the results.

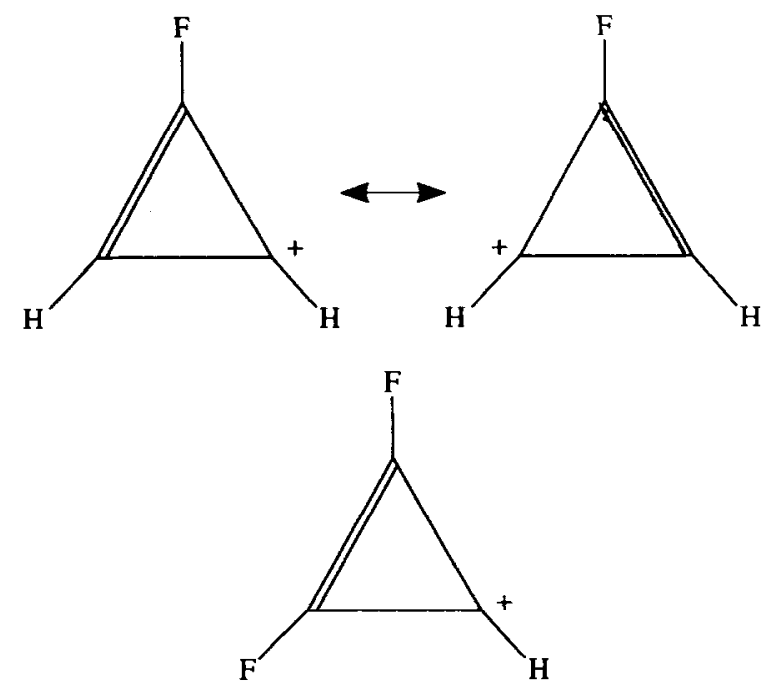

Indeed, it is the $\sigma$ system (in particular the $\sigma$ system re-hybridization processes explained above) that determines the relative values of the $\mathrm{C}-\mathrm{C}$ bond lengths in the studied ions. A good relationship was found between the increase in the $o \mathrm{C}-\mathrm{C}$ overlap populations and the decrease of the $\mathrm{C}-\mathrm{C}$ bond lengths (Fig. 4).

(ii) Both the $\pi$ and $\sigma$ net atomic populations present a complex and non-systematic pattern of variation with the increase in the number of $\mathrm{H} \rightarrow \mathrm{F}$ substitutions. This complex behavior may be due, at least in part, to processes of electron charge transferring involving the fluorine lone electron pairs, though re-hybridization itself may also play an important role in this finding.

In summary, a detailed analysis of the calculated (6-311+ $\left.\mathrm{G}^{*}\right)$ electron distribution of the ions, in particular the changes in the electron distribution associated with successive $\mathrm{H} \rightarrow \mathrm{F}$ substitutions, leads to the conclusion that re-hybridization induced in the carbon atoms by the fluorine substituents and the fluorine $\sigma$ electron withdrawing ability are the main factors which determine their electronic properties. In addition, the differences found in the geometrical parameters of the ions may also be explained, in electronic terms, by considering these two factors. On the contrary, the $\pi$ system was found to be little affected by the $\mathrm{H} \rightarrow \mathrm{F}$ substitutions and does not play any relevant role in determining the relative values of the $\mathrm{C} C$ bond lengths in the studied ions. Finally, each fluorine substituent was found to act almost independently of the others.

\subsection{Vibrational analysis}

Table 11 shows the symmetry coordinates used in this study to perform the vibrational calculations. Four isotopomers of $\mathbf{C P}$ were considered $\left(\mathrm{C}_{3} \mathrm{H}_{3}^{+}, \mathrm{C}_{3} \mathrm{H}_{2} \mathrm{D}^{+}, \mathrm{C}_{3} \mathrm{D}_{2} \mathrm{H}^{+}\right.$and $\left.\mathrm{C}_{3} \mathrm{D}_{3}^{+}\right)$, three of MFCP $\left(\mathrm{C}_{3} \mathrm{H}_{2} \mathrm{~F}^{+}, \mathrm{C}_{3} \mathrm{HDF}^{+}\right.$and $\left.\mathrm{C}_{3} \mathrm{D}_{2} \mathrm{~F}^{+}\right)$, two of DFCP $\left(\mathrm{C}_{3} \mathrm{HF}_{2}^{+}\right.$and $\left.\mathrm{C}_{3} \mathrm{DF}_{2}^{+}\right)$and one of TFCP $\left(\mathrm{C}_{3} \mathrm{~F}_{3}^{+}\right)$. The results are summarized in Tables 12-15, where the $6-311+\mathrm{G}^{*}$ calculated (scaled) frequencies are compared with the experimental values. The fitting of the calculated to the experimental frequencies (scaling) yields the straight line shown in Fig. 5. The general agreement between the calculated and the experimental values is remarkably good for all types of normal modes (with a few exceptions, the agreement of the experimental and calculated frequencies is within 


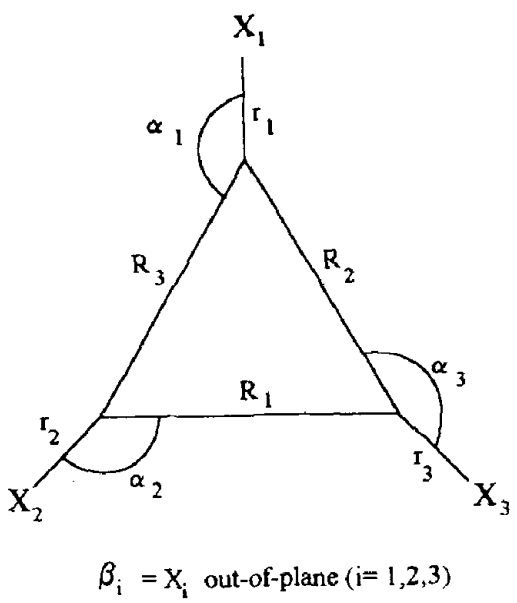

$\mathbf{D}_{\mathbf{3 h}}$

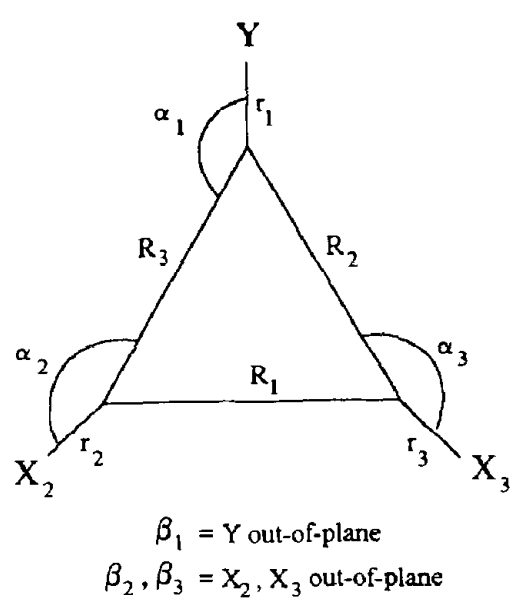

$\mathrm{C}_{2 \mathrm{v}}$

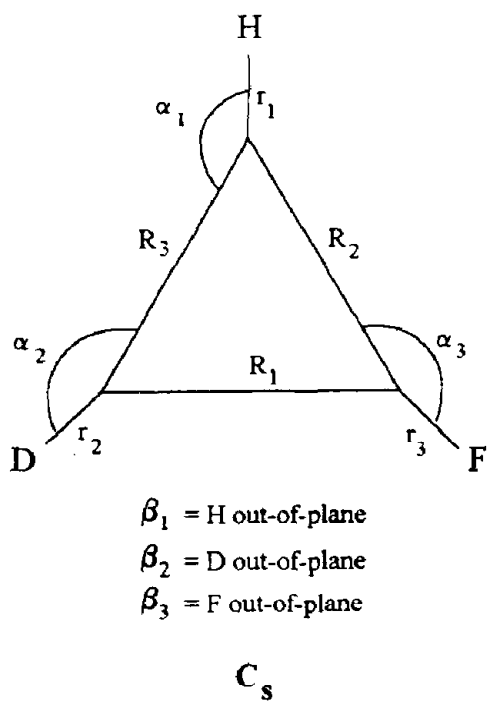

Fig. 3. Internal coordinates definition. $X, Y=H, D, F$.

$2 \%$, and the largest error - which occurs for a very low frequency mode of TFCP - amounts to about $5 \%$, corresponding to only a $16 \mathrm{~cm}^{-1}$ absolute deviation). This excellent general agreement is noteworthy and constitutes additional evidence of the good quality of the electron distribution obtained using the $6-311+G^{*}$ basis set.

In the case of the $\mathbf{C P}$ and its deuterated isotopo- mers, the present calculations give further support to the assignments previously made [15]. For the fluorosubstituted cations, they enable us to confirm or reassign some of the observed bands [21-23]. The new assignments are discussed below: $\mathrm{C}_{3} \mathrm{H}_{2} \mathrm{~F}^{+}$. The bands at 1372 and $1339 \mathrm{~cm}^{-1}$, previously ascribed doubtfully to the $\nu \mathrm{C}-\mathrm{C}$ asym $b_{1}$ and $\nu \mathrm{C}-\mathrm{C} a_{1}$ vibrations, respectively [21], are now assigned inversely, as the calculations clearly 


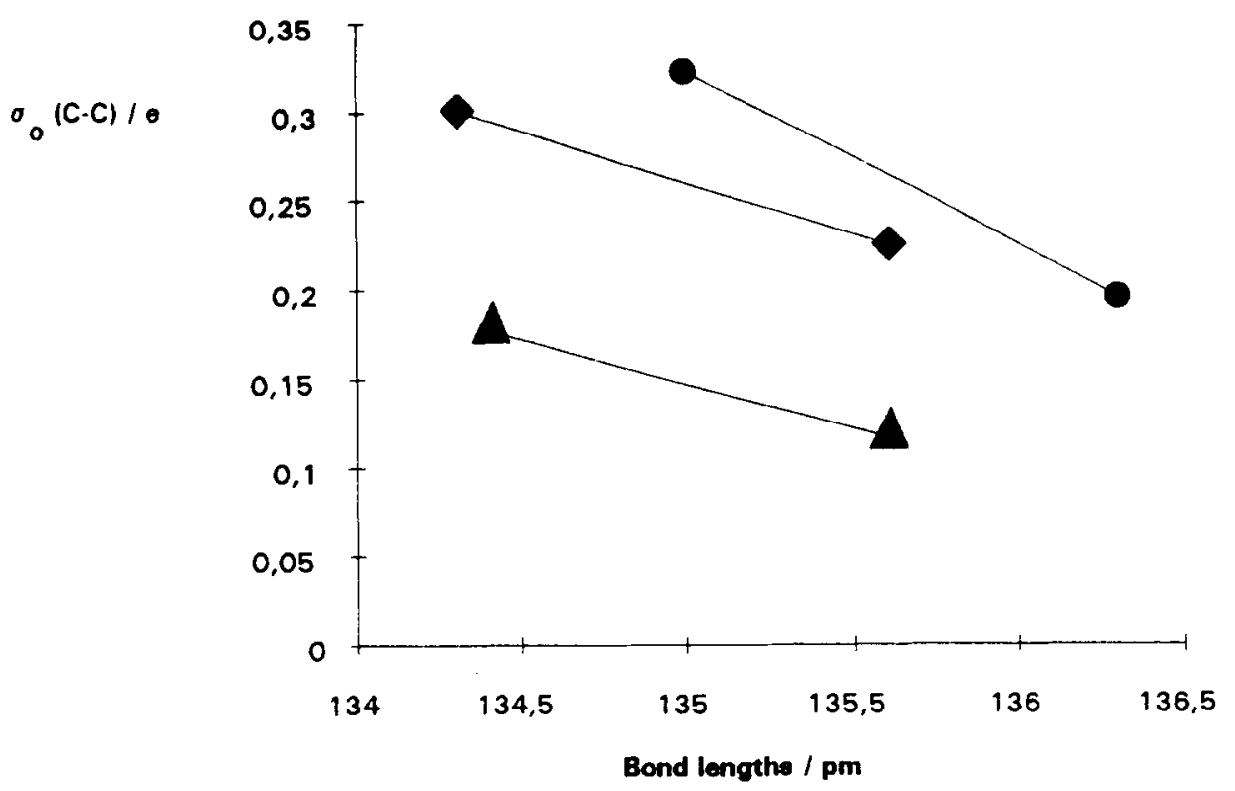

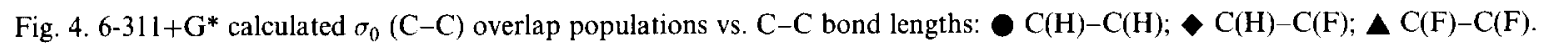

predict that the $a_{1}$ mode has a higher frequency than the $b_{1}$ vibration. The same happens with respect to the $\omega \mathrm{CF} b_{2}$ and $\delta \mathrm{CF} b_{1}$ normal modes, which are now also reassigned inversely to the tentative assignments made in Ref. [21]. Thus, the $b_{2}$ mode is now assigned to the band at $483 \mathrm{~cm}^{-1}$ (calculated frequency $485 \mathrm{~cm}^{-1}$ ), while the $b_{1}$ mode is ascribed to the shoulder appearing at $477 \mathrm{~cm}^{-1}$ (calculated value, $476 \mathrm{~cm}^{-1}$ ). The unobserved $\omega \mathrm{CH}$ asym $a_{2}$ vibration is predicted to have a frequency very close to that of the $\delta \mathrm{CH}$ sym $a_{1}$ mode ( $996 \mathrm{vs.}$ $993 \mathrm{~cm}^{-1}$ ) and is probably hidden underneath the band ascribed to this latter vibration (about $990 \mathrm{~cm}^{-1}$ ). The previously suggested frequency for the $\omega \mathrm{CH}$ asym $a_{2}$ mode $\left(944 \mathrm{~cm}^{-1}\right.$, based in a simplified valence force field normal coordinate analysis [21]) is thus considerably underestimated. This conclusion is further reinforced by looking at both the experimental and calculated frequencies for this vibration in $\mathrm{C}_{3} \mathrm{H}_{2} \mathrm{D}^{+}\left(997\right.$ and $990 \mathrm{~cm}^{-1}$, respectively, see Table 12 ).

$C_{3} D_{2} F^{+}$. As in the case of the non-deuterated fluorocyclopropenyl cation, the bands previously ascribed to the $\nu \mathrm{C}-\mathrm{C}$ asym $b_{1}$ and $\nu \mathrm{C}-\mathrm{C} a_{1}$ vibrations are now assigned inversely. In turn, the band at $828 \mathrm{~cm}^{-1}$, previously assigned to the $\delta \mathrm{CD}$ asym $b_{1}$ mode [21], is now reassigned to the $\omega \mathrm{CD}$ asym $a_{2}$ vibration (calculated value $813 \mathrm{~cm}^{-1}$ ). No assignment for the $a_{2}$ mode was given in Ref. [21], while it was wrongly predicted to occur at about $765 \mathrm{~cm}^{-1}$ (value calculated from normal coordinate analysis using a simplified valence force field). To the $\delta \mathrm{CD}$ asymb $b_{1}$ mode (calculated value $842 \mathrm{~cm}^{-1}$ ) is now assigned the band at $875 \mathrm{~cm}^{-1}$ appearing in the IR spectrum of the $\mathrm{Sb}_{2} \mathrm{~F}_{\mathrm{H}}^{-}$salt of the $\mathrm{C}_{3} \mathrm{D}_{2} \mathrm{~F}^{+}$cation that was not ascribed previously [21].

$\mathrm{C}_{3} H F_{2}^{+}$. All previous assingments [22] of this cation and its deuterated analogue, $\mathrm{C}_{3} \mathrm{DF}_{2}^{+}$, are confirmed by the present calculations. In addition, it is now shown that the band at $924 \mathrm{~cm}^{-1}$ in the spectra of the non-deuterated molecule corresponds to the $\nu \mathrm{C}-\mathrm{F}$ asym $b_{1}$ mode (calculated value $935 \mathrm{~cm}^{-1}$ ). In Ref. [22], this band was assigned doubtfully to either this mode or the $\omega \mathrm{CH} \quad b_{1}$ vibration. However, this latter has a slightly larger frequency (calculated value $942 \mathrm{~cm}^{-1}$ ) and should correspond to the band observed at $946 \mathrm{~cm}^{-1}$ or, at least, contribute to it (in the experimental study, this band was assigned to a vibration of the fluorosulfite ester cation $\mathrm{C}_{3} \mathrm{FHSO}_{2} \mathrm{~F}^{+}$, which is formed from $\mathrm{C}_{3} \mathrm{HF}_{2}^{+}$and the solvent $\left(\mathrm{SO}_{2}\right)$ when the temperature is raised above $-25^{\circ} \mathrm{C}$ ). The $\omega \mathrm{CH} b_{1}$ vibration in $\mathrm{C}_{3} \mathrm{HD}_{2}^{+}$ 
Table 11

Definition of symmetry coordinates ${ }^{\mathrm{a}}$

\begin{tabular}{|c|c|c|c|}
\hline $\begin{array}{l}\text { Symmetry } \\
\text { species }\end{array}$ & Coordinate & $\begin{array}{l}\text { Approximate } \\
\text { description }\end{array}$ & Definition \\
\hline \multicolumn{4}{|c|}{$C_{3} X_{3}^{+}$(Point group: $\mathrm{D}_{3 h}$ ) } \\
\hline$a_{1}^{\prime}$ & $S_{1}$ & $\nu \mathrm{C}-\mathrm{X}$ sym & $\left(\Delta r_{1}+\Delta r_{2}+\Delta r_{3}\right) / \sqrt{3}$ \\
\hline$a_{1}^{\prime}$ & $S_{2}$ & $\nu C-\mathrm{C}$ sym & $\left(\Delta R_{1}+\Delta R_{2}+\Delta R_{3}\right) / \sqrt{3}$ \\
\hline$a_{2}^{i}$ & $S_{3}$ & $\delta \mathrm{CX}$ sym & $\left(\Delta \alpha_{1}+\Delta \alpha_{2}+\Delta \alpha_{3}\right) / \sqrt{3}$ \\
\hline$e^{\prime}$ & $S_{4 \mathrm{a}}$ & $\nu \mathrm{C}-\mathrm{X}$ asym (a) & $\left(2 \Delta r_{1}-\Delta r_{2}-\Delta r_{3}\right) / 2$ \\
\hline$e^{\prime}$ & $S_{4 \mathrm{~b}}$ & $\nu \mathrm{C}-\mathrm{X}$ asym (b) & $\left(\Delta r_{2}-\Delta r_{3}\right) / \sqrt{2}$ \\
\hline$e^{\prime}$ & $S_{5 a}$ & $\nu \mathrm{C}-\mathrm{C}$ asym $(\mathrm{a})$ & $\left(2 \Delta R_{1}-\Delta R_{2}-\Delta R_{3}\right) / 2$ \\
\hline$e^{\prime}$ & $S_{5 \mathrm{~b}}$ & $\nu \mathrm{C}-\mathrm{C}$ asym (b) & $\left(\Delta R_{2}-\Delta R_{3}\right) / \sqrt{2}$ \\
\hline$e^{\prime}$ & $S_{6 a}$ & $\delta \mathrm{CX}$ asym & $\left(2 \Delta \alpha_{1}-\Delta \alpha_{2}-\Delta \alpha_{3}\right) / 2$ \\
\hline$e^{\prime}$ & $S_{6 \mathrm{~b}}$ & $8 \mathrm{CX}$ asym & $\left(\Delta \alpha_{2}-\Delta \alpha_{3}\right) / \sqrt{2}$ \\
\hline$a_{2}^{\prime \prime}$ & $S_{7}$ & $\omega \mathrm{CX}$ sym & $\left(\Delta \beta_{1}+\Delta \beta_{2}+\Delta \beta_{3}\right) \sqrt{3}$ \\
\hline$e^{\prime \prime}$ & $S_{8 \mathrm{a}}$ & $\omega C X$ asym (a) & $\left(2 \Delta \beta_{1}-\Delta \beta_{2}-\Delta \beta_{3}\right) / 2$ \\
\hline$e^{\prime \prime}$ & $S_{8 \mathrm{~b}}$ & $\omega \mathrm{CX}$ asym $(\mathrm{b})$ & $\left(\Delta \beta_{2}+\Delta \beta_{3}\right) \sqrt{2}$ \\
\hline \multicolumn{4}{|c|}{$C_{3} X_{2} Y^{-1}$ (Point group: $\left.C_{2 v}\right)$} \\
\hline$a_{1}$ & $S_{1}$ & $\nu \mathrm{C}-\mathrm{X}$ sym & $\left(\Delta r_{2}+\Delta r_{3}\right) / \sqrt{2}$ \\
\hline$a_{1}$ & $S_{2}$ & $\nu \mathrm{C}-\mathrm{Y}$ & $\Delta r_{1}$ \\
\hline$a_{1}$ & $S_{3}$ & $\nu \mathrm{C}-\mathrm{C}$ sym & $\left(\Delta R_{2}+\Delta R_{3}\right) / \sqrt{2}$ \\
\hline$a_{1}$ & $S_{4}$ & $\nu \mathrm{C}-\mathrm{C}$ & $\Delta R_{1}$ \\
\hline$a_{1}$ & $S_{5}$ & $\delta \mathrm{CX}$ sym & $\left(\Delta \alpha_{2}+\Delta \alpha_{3}\right) / \sqrt{2}$ \\
\hline$a_{2}$ & $S_{6}$ & $\omega \mathrm{CX}$ asym & $\left(\Delta \beta_{2}-\Delta \beta_{3}\right) / \sqrt{2}$ \\
\hline$b_{1}$ & $S_{7}$ & $\nu \mathrm{C}-\mathrm{X}$ asym & $\left(\Delta r_{2}-\Delta r_{3}\right) / \sqrt{2}$ \\
\hline$b_{1}$ & $S_{8}$ & $\nu \mathrm{C}-\mathrm{C}$ asym & $\left(\Delta R_{2}-\Delta R_{3}\right) / \sqrt{2}$ \\
\hline$b_{1}$ & $S_{9}$ & $\delta \mathrm{CX}$ asym & $\left(\Delta \alpha_{2}-\Delta \alpha_{3}\right) / \sqrt{2}$ \\
\hline$b_{1}$ & $S_{10}$ & $\delta \mathrm{CY}$ & $\Delta \alpha_{1}$ \\
\hline$b_{2}$ & $S_{11}$ & $\omega \mathrm{CX}$ sym & $\left(\Delta \beta_{2}+\Delta \beta_{3}\right) / \sqrt{2}$ \\
\hline$b_{2}$ & $S_{12}$ & $\omega \mathrm{CY}$ & $\Delta \beta_{1}$ \\
\hline \multicolumn{4}{|c|}{$C_{3} H D F^{+}$(Point group: $\mathrm{C}_{S}$ ) } \\
\hline$a^{\prime}$ & $S_{1}$ & $\nu \mathrm{C}-\mathrm{H}$ & $\Delta r_{1}$ \\
\hline$a^{\prime}$ & $S_{2}$ & $\nu \mathrm{C}-\mathrm{D}$ & $\Delta r_{2}$ \\
\hline$a^{\prime}$ & $S_{3}$ & $\nu \mathrm{C}-\mathrm{F}$ & $\Delta r_{3}$ \\
\hline$a^{\prime}$ & $S_{4}$ & $\nu \mathrm{C}-\mathrm{C}(1)$ & $\Delta R_{1}$ \\
\hline$a^{\prime}$ & $S_{5}$ & $\nu \mathrm{C}-\mathrm{C}(2)$ & $\Delta R_{2}$ \\
\hline$a^{\prime}$ & $S_{6}$ & ${ }_{\nu} \mathrm{C}-\mathrm{C}(3)$ & $\Delta R_{3}$ \\
\hline$a^{\prime}$ & $S_{7}$ & $\delta \mathrm{CH}$ & $\Delta \alpha_{1}$ \\
\hline$a^{\prime}$ & $S_{8}$ & $\delta \mathrm{CD}$ & $\Delta \alpha_{2}$ \\
\hline$a^{\prime}$ & $S_{9}$ & $\delta \mathrm{CF}$ & $\Delta \alpha_{3}$ \\
\hline$a^{\prime \prime}$ & $S_{10}$ & $\omega \mathrm{CH}$ & $\Delta \beta_{1}$ \\
\hline$a^{\prime \prime}$ & $s_{11}$ & $\omega C D$ & $\Delta \beta_{2}$ \\
\hline$a^{\prime \prime}$ & $S_{12}$ & $\omega \mathrm{CF}$ & $\Delta \beta_{3}$ \\
\hline
\end{tabular}

\footnotetext{
a $\mathrm{X}, \mathrm{Y}=\mathrm{H}, \mathrm{D}, \mathrm{F}$; see Fig. 3 for definition of the internal coordinates; $\nu$, stretching; $\delta$, in-plane bending, $\omega$, out-of-plane bending; sym,
} symmetric; asym, asymmetric.

gives rise to a band at about $960 \mathrm{~cm}^{-1}$ (see Table 12) which reinforces the present assignments.

$C_{3} F_{3}^{+}$. The calculations confirm the assignments previously made [23]. However, two modes remained to be assigned in the experimental work ( $\delta \mathrm{CF}$ sym $a_{2}^{\prime}$ and $\omega \mathrm{CF}$ sym $a_{2}^{\prime \prime}$ ). These were pre- dicted to give rise to frequencies at about 811 and $239 \mathrm{~cm}^{-1}$, respectively, by normal coordinate analysis using a simplified valence force field [23]. However, the present calculations show that these values were considerably overestimated and underestimated, respectively. In fact, the $6-311+\mathrm{G}^{*}$ 
Table 12

Calculated and experimental vibrational frequencies $\left(\mathrm{cm}^{-1}\right)$ of $\mathrm{C}_{3} \mathrm{H}_{3}^{+}, \mathrm{C}_{3} \mathrm{H}_{2} \mathrm{D}^{+}, \mathrm{C}_{3} \mathrm{D}_{2} \mathrm{H}^{+}$and $\mathrm{C}_{3} \mathrm{D}_{3}^{+}$and corresponding potential energy distribution (PED) ${ }^{\mathrm{a}}$

\begin{tabular}{|c|c|c|c|c|}
\hline $\begin{array}{l}\text { Approximate } \\
\text { description }\end{array}$ & Symmetry & $\operatorname{Exp}^{b}$ & Calc. & $\mathrm{PED}^{\mathrm{C}}$ \\
\hline \multicolumn{5}{|l|}{$\mathrm{C}_{3} \mathrm{H}_{3}^{+}$} \\
\hline$\nu \mathrm{C}-\mathrm{H}$ sym & $a_{1}^{\prime}$ & 3183 & 3186 & $S_{1}[95]+S_{2}[5]$ \\
\hline$\nu \mathrm{C}-\mathrm{H}$ asym & $e^{\prime}$ & 3138 & 3136 & $S_{4}(a)[64]+S_{4}(b)[35]$ \\
\hline$\nu \mathrm{C}-\mathrm{C}$ sym & $a_{1}^{\prime}$ & 1626 & 1619 & $S_{2}[96]+S_{1}[5]$ \\
\hline$\nu \mathrm{C}-\mathrm{C}$ asym & $e^{\prime}$ & 1290 & 1276 & $S_{5}(a)[49]+S_{5}(b)[45]+S_{6}(a)[17]$ \\
\hline$\delta \mathrm{CH}$ sym & $a_{2}^{\prime}$ & $1031^{d}$ & 1047 & $S_{3}[100]$ \\
\hline wCH asym & $e^{\prime \prime}$ & $990^{d}$ & 998 & $S_{8}(a)[98]$ \\
\hline$\delta \mathrm{CH}$ asym & $e^{\prime}$ & 927 & 925 & $S_{6}(a)[83]+S_{5}(b)[10]$ \\
\hline$\omega \mathrm{CH}$ sym & $a_{2}^{\prime \prime}$ & 758 & $76 !$ & $S_{7}[100]$ \\
\hline \multicolumn{5}{|l|}{$C_{3} H_{2} D^{+}$} \\
\hline$\nu \mathrm{C}-\mathrm{H}$ sym & $a_{1}$ & $3166^{\mathrm{e}}$ & 3169 & $S_{1}[96]$ \\
\hline$\nu \mathrm{C}-\mathrm{H}$ asym & $b_{1}$ & 3134 & 3136 & $S_{7}[99]$ \\
\hline$\nu \mathrm{C}-\mathrm{D}$ & $a_{1}$ & 2389 & 2373 & $S_{2}[89]+S_{3}[11]$ \\
\hline$\nu \mathrm{C}-\mathrm{C}$ sym & $a_{1}$ & 1583 & 1572 & $S_{3}[52]+S_{4}[45]+S_{2}[8]$ \\
\hline$\nu \mathrm{C}-\mathrm{C}$ asym & $b_{1}$ & 1286 & 1270 & $S_{8}[95]+S_{10}[6]$ \\
\hline$\nu \mathrm{C}-\mathrm{C}$ & $a_{1}$ & 1267 & 1253 & $S_{4}[50]+S_{3}[34]+S_{5}[28]$ \\
\hline$\delta \mathrm{CH}$ asym & $b_{1}$ & $1008^{d}$ & 1021 & $S_{9}[97]+S_{10}[9]$ \\
\hline$\omega \mathrm{CH}$ asym & $a_{2}$ & $990^{\mathrm{d}}$ & 997 & $S_{6}[100]$ \\
\hline$\delta \mathrm{CH}$ sym & $a_{1}$ & 924 & 923 & $S_{5}[76]+S_{4}[7]$ \\
\hline$\omega \mathrm{CH}$ sym & $b_{2}$ & 920 & 911 & $S_{11}[68]+S_{12}[23]$ \\
\hline$\delta \mathrm{CD}$ & $b_{1}$ & 718 & 716 & $S_{10}[87]$ \\
\hline$\omega C D$ & $b_{2}$ & $655^{\mathrm{d}}$ & 656 & $S_{12}[78]+S_{11}[33]$ \\
\hline \multicolumn{5}{|l|}{$C_{3} D_{2} H^{+}$} \\
\hline$\nu \mathrm{C}-\mathrm{H}$ & $a_{1}$ & 3154 & 3154 & $S_{2}[98]$ \\
\hline$\nu \mathrm{C}-\mathrm{D}$ sym & $a_{1}$ & 2420 & 2418 & $S_{1}[84]+S_{4}[10]+S_{3}[6]$ \\
\hline$\nu \mathrm{C}-\mathrm{D}$ asym & $b_{1}$ & 2354 & 2326 & $S_{7}[96]$ \\
\hline$v \mathrm{C}-\mathrm{C}$ sym & $a_{1}$ & $1536^{\mathrm{e}}$ & 1527 & $S_{3}[71]+S_{4}[20]+S_{1}[14]$ \\
\hline$\nu \bar{C}-\mathrm{C}$ & $a_{1}$ & 1268 & 1252 & $S_{4}[72]+S_{3}[21]+S_{5}[17]$ \\
\hline$\nu \mathrm{C}-\mathrm{C}$ asym & $b_{1}$ & 1256 & 1242 & $S_{8}[88]+S_{10}[14]$ \\
\hline$\delta \mathrm{CH}$ & $b_{1}$ & 973 & 985 & $S_{10}[80]+S_{9}[13]+S_{8}[6]$ \\
\hline$\omega \mathrm{CH}$ & $b_{2}$ & 960 & 959 & $S_{12}[86]+S_{11}[9]$ \\
\hline$\omega \mathrm{CD}$ asym & $a_{2}$ & 807 & 809 & $S_{11}[100]$ \\
\hline$\delta \mathrm{CD}$ sym & $a_{1}$ & 767 & 767 & $S_{9}[89]+S_{10}[7]$ \\
\hline$\delta \mathrm{CD}$ asym & $b_{1}$ & 675 & 670 & $S_{5}[87]$ \\
\hline$\omega C D$ sym & $b_{2}$ & 603 & 601 & $S_{11}[93]+S_{12}[15]$ \\
\hline \multicolumn{5}{|l|}{$C_{3} D_{3}^{+}$} \\
\hline$\nu \mathrm{C}-\mathrm{D}$ sym & $a_{1}^{\prime}$ & $2471^{e}$ & 2461 & $S_{1}[79]+S_{2}[20]$ \\
\hline$\nu \mathrm{C}-\mathrm{D}$ asym & $e^{\prime}$ & 2348 & 2326 & $S_{4}(a)[58]+S_{4}(b)[38]$ \\
\hline$\nu \mathrm{C}-\mathrm{C}$ sym & $a_{1}^{\prime}$ & 1490 & 1481 & $S_{2}[80]+S_{1}[20]$ \\
\hline$\nu \mathrm{C}-\mathrm{C}$ asym & $e^{i}$ & 1248 & 1232 & $S_{5}(a)[62]+S_{5}(b)[34]+S_{6}(b)[13]$ \\
\hline$\delta \mathrm{CD}$ sym & $a_{2}^{\prime}$ & $837^{\mathrm{d}}$ & 849 & $S_{3}[100]$ \\
\hline$\omega \mathrm{CD}$ asym & $e^{\prime \prime}$ & 802 & 809 & $S_{8}(a)[95]+S_{8}(b)[6]$ \\
\hline$\delta \mathrm{CD}$ asym & $e^{\prime}$ & 674 & 668 & $S_{6}(a)[89]+S_{5}(b)[6]$ \\
\hline$\omega \mathrm{CD}$ sym & $a_{2}^{\prime \prime}$ & 560 & 557 & $S_{7}[100]$ \\
\hline
\end{tabular}

a See Table 11 for definition of symmetry coordinates; $\nu$, stretching; $\delta$, in-plane bending; $\omega$; out-of-plane bending; sym, symmetric; asym, asymmetric.

${ }^{\mathrm{b}}$ From spectra in $\mathrm{SO}_{2}$ solution [15]. Value in italic was obtained from the $\mathrm{C}_{3} \mathrm{D}_{3}^{+}$salt of $\mathrm{BF}_{4}^{-}$[15].

${ }^{\mathrm{c}}$ Only PEDs greater than $5 \%$ are shown; in the case of degenerate modes, only the PED corresponding to that vibration involving mainly the $(a)$ coordinate is shown.

${ }^{d}$ Calculated values [15] including anharmonic corrections.

' Modified for excluding Fermi resonance [15]. 
Tablc 13

Calculated and experimental vibrational frequencies $\left(\mathrm{cm}^{-1}\right)$ of $\mathrm{C}_{3} \mathrm{H}_{2} \mathrm{~F}^{+}, \mathrm{C}_{3} \mathrm{HDF}^{+}$and $\mathrm{C}_{3} \mathrm{D}_{2} \mathrm{~F}^{+}$and corresponding potential energy distribution (PED) ${ }^{\mathrm{a}}$

\begin{tabular}{|c|c|c|c|c|}
\hline $\begin{array}{l}\text { Approximate } \\
\text { description }\end{array}$ & Symmetry & Exp. & Cal. & $\mathrm{PED}^{\mathrm{c}}$ \\
\hline $\begin{array}{l}\mathrm{C}_{3} \mathrm{H}_{2} \mathrm{~F}^{+} \\
\nu \mathrm{C}-\mathrm{H} \text { sym } \\
\nu \mathrm{C}-\mathrm{H} \text { asym } \\
\nu \mathrm{C}-\mathrm{C} \text { sym } \\
\nu \mathrm{C}-\mathrm{C} \\
\nu \mathrm{C}-\mathrm{C} \text { asym } \\
\delta \mathrm{CH} \text { asym } \\
\omega \mathrm{CH} \text { asym } \\
\delta \mathrm{CH} \text { sym } \\
\omega \mathrm{CH} \text { sym } \\
\nu \mathrm{C}-\mathrm{F} \\
\omega \mathrm{CF} \\
\delta \mathrm{CF}\end{array}$ & $\begin{array}{l}a_{1} \\
b_{1} \\
a_{1} \\
a_{1} \\
b_{1} \\
b_{1} \\
a_{2} \\
a_{1} \\
b_{2} \\
a_{1} \\
b_{2} \\
b_{1}\end{array}$ & $\begin{array}{c}3153 \\
3119 \\
1835 \\
1372 \\
1339 \\
1022 \\
\text { n.o. } \\
988 \\
876 \\
830 \\
483 \\
477\end{array}$ & $\begin{array}{r}3159 \\
3130 \\
1858 \\
1365 \\
1340 \\
1033 \\
996 \\
993 \\
883 \\
832 \\
485 \\
476\end{array}$ & $\begin{array}{l}S_{1}[96] \\
S_{7}[99] \\
S_{3}[63]+S_{2}[39]+S_{4}[7] \\
S_{4}[85]+S_{2}[17]+S_{5}[14] \\
S_{8}[91]+S_{10}[6] \\
S_{9}[99]+S_{10}[8] \\
S_{6}[100] \\
S_{5}[73]+S_{2}[22]+S_{3}[13] \\
S_{11}[83]+S_{12}[11] \\
S_{3}[27]+S_{2}[23]+S_{5}[18]+S_{4}[12] \\
S_{12}[91]+S_{11}[20] \\
S_{10}[87]+S_{8}[7]\end{array}$ \\
\hline $\begin{array}{l}C_{3} H D F^{+} \\
\nu \mathrm{CH} \\
\nu \mathrm{C}-\mathrm{D} \\
\nu \mathrm{C}-\mathrm{C}(2) \\
\nu \mathrm{C}-\mathrm{C}(3) \\
\nu \mathrm{C}-\mathrm{C}(1) \\
\delta \mathrm{CH} \\
\omega \mathrm{CH} \\
\nu \mathrm{C}-\mathrm{F} \\
\omega \mathrm{CD} \\
\delta \mathrm{CD} \\
\omega \mathrm{CF} \\
\delta \mathrm{CF}\end{array}$ & $\begin{array}{l}a^{\prime} \\
a^{\prime} \\
a^{\prime} \\
a^{\prime} \\
a^{\prime} \\
a^{\prime} \\
a^{\prime \prime} \\
a^{\prime} \\
a^{\prime \prime} \\
a^{\prime} \\
a^{\prime \prime} \\
a^{\prime}\end{array}$ & $\begin{array}{l}- \\
- \\
- \\
- \\
- \\
- \\
- \\
- \\
- \\
- \\
- \\
-\end{array}$ & $\begin{array}{r}3144 \\
2374 \\
1836 \\
1349 \\
1305 \\
1011 \\
952 \\
904 \\
761 \\
718 \\
457 \\
452\end{array}$ & $\begin{array}{l}S_{1}[98] \\
S_{2}[87]+S_{4}[8]+S_{6}[5] \\
S_{3}[49]+S_{5}[36]+S_{4}[26]+S_{2}[7] \\
S_{6}[61]+S_{5}[14]+S_{4}[13]+S_{3}[12] \\
S_{4}[31]+S_{5}[28]+S_{6}[24]+S_{9}[8]+S_{2}[5] \\
S_{7}[88]+S_{3}[8]+S_{4}[5] \\
S_{10}[87]+S_{11}[6] \\
S_{3}[33]+S_{8}[30]+S_{5}[17]+S_{4}[14]+S_{9}[7] \\
S_{11}[72]+S_{12}[20] \\
S_{8}[58]+S_{6}[6]+S_{7}[5] \\
S_{12}[80]+S_{11}[24]+S_{10}[12] \\
S_{9}[80]+S_{8}[9]\end{array}$ \\
\hline $\begin{array}{l}C_{3} D_{2} F^{+} \\
\nu \mathrm{C}-\mathrm{D} \text { sym } \\
\nu \mathrm{C}-\mathrm{D} \text { asym } \\
\nu \mathrm{C}-\mathrm{C} \text { sym } \\
\nu \mathrm{C}-\mathrm{C} \\
\nu \mathrm{C}-\mathrm{C} \text { asym } \\
\nu \mathrm{C}-\mathrm{F} \\
\delta \mathrm{CD} \text { asym } \\
\omega \mathrm{CD} \text { asym } \\
\omega \mathrm{CD} \text { sym } \\
\delta \mathrm{CD} \text { sym } \\
\delta \mathrm{CF} \\
\omega \mathrm{CF}\end{array}$ & $\begin{array}{l}a_{1} \\
b_{1} \\
a_{1} \\
a_{1} \\
b_{1} \\
a_{1} \\
b_{1} \\
a_{2} \\
b_{2} \\
a_{1} \\
b_{1} \\
b_{2}\end{array}$ & $\begin{array}{r}2426 \\
2353 \\
1790 \\
1331 \\
1289 \\
914 \\
875 \\
828 \\
732 \\
650 \\
446 \\
424\end{array}$ & $\begin{array}{r}2419 \\
2327 \\
1802 \\
1306 \\
1296 \\
914 \\
842 \\
813 \\
742 \\
645 \\
435 \\
428\end{array}$ & $\begin{array}{l}S_{1}[81]+S_{4}[10]+S_{3}[10] \\
S_{7}[95]+S_{8}[5] \\
S_{3}[54]+S_{2}[44]+S_{1}[11] \\
S_{4}[86]+S_{2}[12]+S_{5}[10]+S_{1}[7] \\
S_{8}[89]+S_{10}[7] \\
S_{2}[42]+S_{3}[35]+S_{5}[22] \\
S_{7}[90]+S_{10}[17] \\
S_{6}[100] \\
S_{11}[60]+S_{12}[30] \\
S_{5}[73]+S_{4}[6]+S_{3}[5] \\
S_{10}[77]+S_{7}[12]+S_{8}[8] \\
S_{12}[72]+S_{11}[43]\end{array}$ \\
\hline
\end{tabular}

${ }^{a}$ See Table 11 for definition of symmetry coordinates; $\nu$, stretching; $\delta$, in-plane bending; $\omega$, out-of-plane bending; sym, symmetric; asym, asymmetric; n.o., not observed.

${ }^{\mathrm{h}}$ From spectra in $\mathrm{SO}_{2}$ solution [21]; values in italic were obtained for $\mathrm{C}_{3} \mathrm{H}_{2} \mathrm{~F}^{\prime}$ or $\mathrm{C}_{3} \mathrm{D}_{2} \mathrm{~F}^{1}$ salts of $\mathrm{BF}_{4}^{-}$or $\mathrm{Sb}_{2} \mathrm{~F}_{11}^{-}[21]$.

${ }^{c}$ Only PEDs greater than $5 \%$ are shown.

(scaled) calculated frequency for the $\delta \mathrm{CF}$ sym $a_{2}^{\prime}$ mode is $769 \mathrm{~cm}^{-1}$, while that corresponding to the $\omega \mathrm{CF}$ sym $a_{2}^{\prime \prime}$ vibrations is $256 \mathrm{~cm}^{-1}$. It is interesting to note that bands close to these two frequencies were observed experimentally $\left(767\right.$ and $257 \mathrm{~cm}^{-1}$
[23]), though they were assigned in the experimental work to other species $\left(\mathrm{BF}_{4}^{-}\right.$and $\mathrm{C}_{3} \mathrm{~F}_{4} / \mathrm{B}_{2} \mathrm{~F}_{7}^{-}$or $\mathrm{Sb}_{2} \mathrm{~F}_{11}^{-}$). Indeed, we believe that the two vibrations of the $\mathrm{C}_{3} \mathrm{~F}_{3}^{+}$cation not assigned previously contribute in some extent to these bands. 
Table 14

Calculated and experimental vibrational frequencies $\left(\mathrm{cm}^{-1}\right)$ of $\mathrm{C}_{3} \mathrm{HF}_{2}^{+}$and $\mathrm{C}_{3} \mathrm{DF}_{2}^{+}$and corresponding potential energy distribution $(\mathrm{PED})^{\mathrm{a}}$

\begin{tabular}{|c|c|c|c|c|}
\hline $\begin{array}{l}\text { Approximate } \\
\text { description }\end{array}$ & Symmetry & Exp. ${ }^{b}$ & Calc. & $\mathrm{PED}^{\mathrm{c}}$ \\
\hline \multicolumn{5}{|l|}{$\mathrm{C}_{3} H F_{2}^{+}$} \\
\hline$\nu \mathrm{C}-\mathrm{H}^{2}$ & $a_{1}$ & 3126 & 3136 & $S_{2}[98]$ \\
\hline$\nu \mathrm{C}-\mathrm{C}$ & $a_{1}$ & 1945 & 1969 & $S_{1}[43]+S_{4}[40]+S_{3}[30]$ \\
\hline$\nu \mathrm{C}-\mathrm{C}$ asym & $b_{1}$ & 1541 & 1582 & $S_{7}[67]+S_{8}[46]$ \\
\hline$\nu \mathrm{C}-\mathrm{C}$ sym & $a_{1}$ & 1393 & 1383 & $S_{3}[59]+S_{4}[25]+S_{5}[16]$ \\
\hline$\delta \mathrm{CH}$ & $b_{1}^{\prime}$ & 1025 & 1058 & $S_{10}[72]+S_{7}[16]+S_{8}[14]$ \\
\hline$\omega \mathrm{CH}$ & $b_{2}$ & 946 & 942 & $S_{12}[90]$ \\
\hline$\nu \mathrm{C}-\mathrm{F}$ asym & $b_{1}$ & 924 & 935 & $S_{8}[34]+S_{10}[21]+S_{7}[18]+S_{9}[13]$ \\
\hline$\nu \mathrm{CF}$ sym & $a_{1}$ & 843 & 844 & $S_{1}[53]+S_{4}[31]+S_{3}[8]+S_{5}[7]$ \\
\hline$\omega \mathrm{CF}$ asym & $a_{2}$ & 650 & 664 & $S_{6}[100]$ \\
\hline$\delta \mathrm{CF}$ asym & $b_{1}$ & 582 & 584 & $S_{9}[89]+S_{8}[11]+S_{10}[5]$ \\
\hline$\omega C F$ sym & $b_{2}$ & 366 & 364 & $S_{11}[100]+S_{12}[13]$ \\
\hline$\delta$ CF sym & $a_{1}$ & 311 & 296 & $S_{5}[79]+S_{4}[8]$ \\
\hline \multicolumn{5}{|l|}{$C_{3} D F_{2}^{+}$} \\
\hline$\nu \mathrm{C}-\mathrm{D}$ & $a_{1}$ & 2379 & 2375 & $S_{2}[84]+S_{3}[14]$ \\
\hline$\nu \mathrm{C}-\mathrm{C}$ & $a_{1}$ & 1923 & 1938 & $S_{1}[44]+S_{4}[42]+S_{3}[19]+S_{2}[8]$ \\
\hline$\nu \mathrm{C}-\mathrm{C}$ asym & $b_{1}$ & 1540 & 1580 & $S_{7}[67]+S_{8}[46]$ \\
\hline$\nu \mathrm{C}-\mathrm{C}$ sym & $a_{1}$ & 1347 & 1333 & $S_{3}[57]+S_{4}[23]+S_{5}[16]+S_{2}[7]$ \\
\hline$\nu \mathrm{C}-\mathrm{F}$ asym & $b_{1}$ & 971 & 988 & $S_{8}[46]+S_{7}[33]+S_{10}[13]$ \\
\hline$\nu \mathrm{C}-\mathrm{F}$ sym & $a_{1}$ & 837 & 839 & $S_{1}[53]+S_{4}[30]+S_{3}[10]+S_{5}[6]$ \\
\hline$\delta \mathrm{CD}$ & $b_{1}$ & 806 & 823 & $S_{10}[61]+S_{9}[40]$ \\
\hline$\omega \mathrm{CD}$ & $b_{2}$ & 762 & 774 & $S_{12}[81]+S_{11}[10]$ \\
\hline$\omega \mathrm{CF}$ asym & $a_{2}$ & 650 & 664 & $S_{6}[100]$ \\
\hline$\delta \mathrm{CF}$ asym & $b_{1}$ & 521 & 513 & $S_{9}[64]+S_{10}[25]+S_{8}[11]$ \\
\hline$\omega C F$ sym & $b_{2}$ & 340 & 337 & $S_{11}[94]+S_{12}[22]$ \\
\hline$\delta \mathrm{CF}$ sym & $a_{1}$ & 309 & 294 & $S_{5}[79]+S 4[8]$ \\
\hline
\end{tabular}

${ }^{a}$ See Table 11 for definition of symmetry coordinates; $\nu$, stretching; $\delta$, in-plane bending; $\omega$, out-of-plane bending; sym, symmetric; asym, asymmetric.

${ }^{\mathrm{b}}$ From spectra in $\mathrm{SO}_{2}$ solution [22]; values in italic were obtained for $\mathrm{C}_{3} \mathrm{HF}_{2}^{+}$or $\mathrm{C}_{3} \mathrm{DF}_{2}^{+}$salts of $\mathrm{BF}_{4}^{-}$or $\mathrm{Sb}_{2} \mathrm{~F}_{11}^{-}[22]$.

${ }^{\mathrm{c}}$ Only PEDs greater than $5 \%$ are shown.

Table 15

Calculated and experimental vibrational frequencies $\left(\mathrm{cm}^{-1}\right)$ of $\mathrm{C}_{3} \mathrm{~F}_{3}^{+}$and corresponding potential energy distribution (PED)

\begin{tabular}{llrll}
\hline $\begin{array}{l}\text { Approximate } \\
\text { description }\end{array}$ & Symmetry & Exp. & Calc. & PED $^{\mathrm{c}}$ \\
\hline$C_{3} F_{3}^{+}$ & & & & \\
$\nu \mathrm{C}-\mathrm{C}$ sym & $a_{1}^{\prime}$ & 2014 & 2045 & $S_{2}[62]+S_{1}[45]$ \\
$\nu \mathrm{C}-\mathrm{C}$ asym & $e^{\prime}$ & 1590 & 1612 & $S_{4}(a)[48]+S_{5}(a)[38]+S_{4}(b)[15]+S_{5}(b)[12]+S_{6}(a)[5]$ \\
$\nu \mathrm{C}-\mathrm{F}$ asym & $e^{\prime}$ & 999 & 1006 & $S_{5}(a)[25]+S_{4}(a)[22]+S_{5}(b)[18]+S_{4}(b)[16]+S_{6}(b)[13]$ \\
$\delta \mathrm{CF}$ sym & $a_{2}^{\prime}$ & 767 & 769 & $S_{3}[100]$ \\
$\nu \mathrm{C}-\mathrm{F}$ sym & $a_{1}^{\prime}$ & 752 & 752 & $S_{1}[55]+S_{2}[38]$ \\
$\omega \mathrm{CF}$ asym & $e^{\prime \prime}$ & 642 & 660 & $S_{8}(a)[100]$ \\
$\delta \mathrm{CF}$ asym & $e^{\prime}$ & 287 & 271 & $S_{6}(a)[85]+S_{5}(b)[14]$ \\
$\omega \mathrm{CF}$ sym & $a_{2}^{\prime \prime}$ & 257 & 256 & $S_{7}[100]$ \\
\hline
\end{tabular}

a See Table 11 for definition of symmetry coordinates; $\nu$, stretching; $\delta$, in-plane bending; $\omega$, out-of-plane bending; sym, symmetric; asym, asymmetric.

${ }^{b}$ From spectra in $\mathrm{SO}_{2}$ solution [23]; value in italic was obtained for the $\mathrm{C}_{3} \mathrm{~F}_{3}^{+}$salt of $\mathrm{BF}_{4}^{-}$[23].

${ }^{\mathrm{c}}$ Only PEDs greater than $5 \%$ are shown; in the case of degenerate modes, only the PED corresponding to that vibration involving mainly the (a) coordinate is shown. 


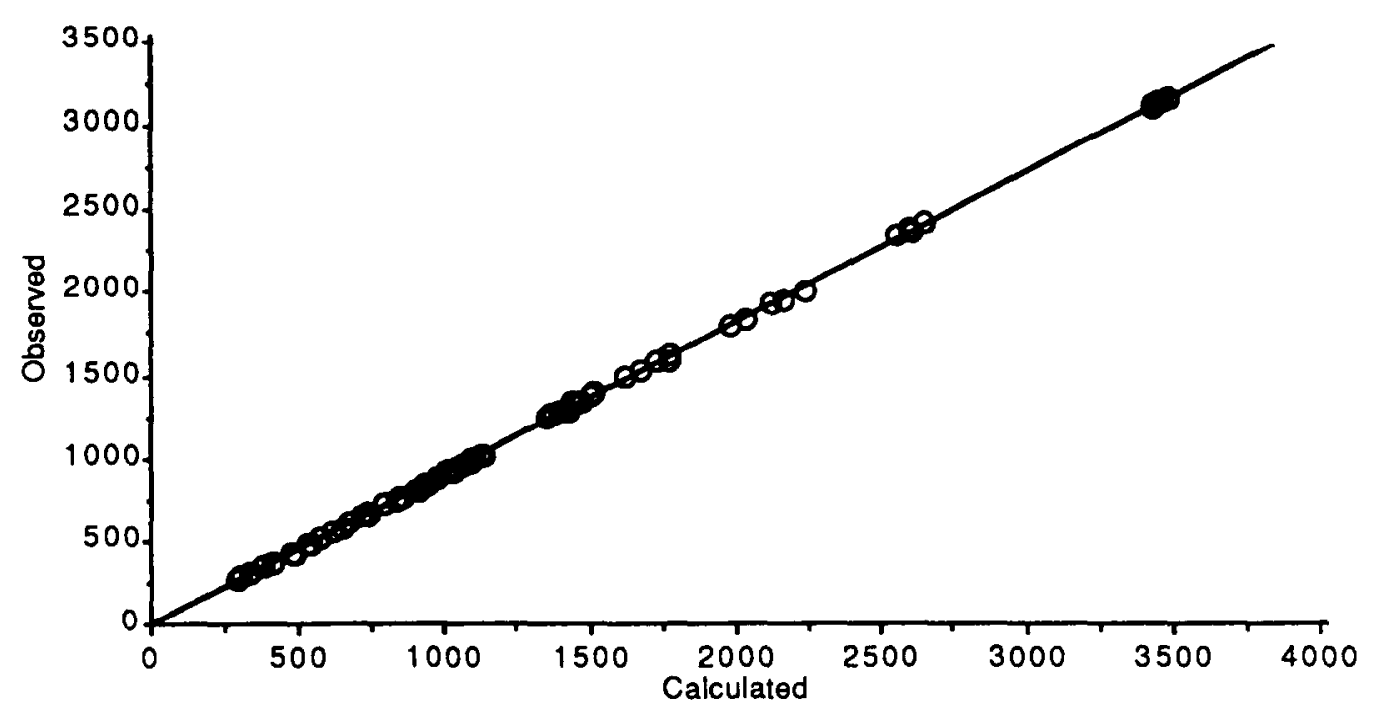

Fig. 5. Calculated vs. experimental vibrational frequencies $\left(\mathrm{cm}^{-1}\right)$ for $\mathbf{C P}, \mathbf{M F C P}, \mathbf{D F C P}$ and TFCP. The straight line resulting from the linear regression is $\nu_{\text {Obs. }}=0.916 \times \nu_{\text {Cal. }}-8.329 ; R^{2}=1$.

The analysis of the potential energy distributions (PEDs) for the various molecules studied here (see Tables 12-15) leads essentially to the same conclusions previously reported in Refs. [15] and [21-23]. The following trends can be drawn:

(i) For the cyclopropenyl cation (and its isotopomers), as well as for the monofluorosubstituted molecules, most of the normal modes are dominated by a single symmetry coordinate.

(ii) In the deuterated compounds some mixing of coordinates can be noticed involving the symmetric $\mathrm{C}-\mathrm{C}$ and $\mathrm{C}-\mathrm{D}$ stretching coordinates.

(iii) Increasing the number of hydrogen-byfluorine substitutions increases the degree of mixing of the symmetry coordinates. In the monofluorosubstituted cation, the $\mathrm{C}-\mathrm{F}$ stretching mixes mainly with the $\mathrm{C}-\mathrm{C}$ symmetric stretching associated with the two adjacent $\mathrm{C}-\mathrm{C}$ bonds (see Table 13); in the disubstituted cation, both the symmetric and the antisymmetric $\mathrm{C}-\mathrm{F}$ stretching coordinates mix strongly with the $\mathrm{C} C$ stretching coordinates (the first, with the two $\mathrm{C}-\mathrm{C}$ stretching coordinates of $a_{1}$ symmetry and the second with the $\mathrm{C}-\mathrm{C}$ antisymmetric stretching coordinate; see Table 14); finally, in the trisubstituted cation, again the $\mathrm{C}-\mathrm{F}$ symmetric and antisymmetric stretching oscillators mix considerably with the $\mathrm{C}-\mathrm{C}$ symmetric and antisymmetric stretching coordinates, respectively.

(iv) The extensive mixing observed between the $\mathrm{C}-\mathrm{C}$ and $\mathrm{C}-\mathrm{F}$ stretching coordinates leads to notably high frequencies for the ring breathing mode in TFCP as well as for the ring mode involving mainly the $\mathrm{C}(\mathrm{F})-\mathrm{C}$ bonds or the $\mathrm{C}(\mathrm{F})$ $\mathrm{C}(\mathrm{F})$ bond in MFCP or DFCP, respectively.

\section{Acknowledgments}

The authors are grateful to Professors Mozart N. Ramos (Departamento de Química Fundamental, Universidade Federal de Pernambuco, Brazil) and Hugh D. Burrows (Departamento de Quimica, Universidade de Coimbra, Portugal) for their helpful comments and suggestions, and to Gustavo L.C. Moura and Huang S. Ciz for their aid in preliminary calculations. This research was financially supported by Junta Nacional de Investigação Científica e Tecnológica (JNICT), Portugal, and Conselho Nacional de Pesquisas $\left(\mathrm{CNP}_{\mathrm{q}}\right)$, Brazil.

\section{References}

[1] R.D. Kern, H.J. Singh and K. Xie, J. Phys. Chem., 94 (1990) 3333. 
[2] J.M. Goodings, D.K. Bohme and C.-W. Ng, Combust. Flame, 36 (1979) 27.

[3] D.B. Olson and H.F. Calcote, Proc. 18th Int. Symp. on Combusion, 1981, p. 453.

[4] P. Michauld, J.L. Delfau and A. Barrasin, Proc. 18th Int. Symp. on Combustion, 1981, p. 443.

[5] S.A. Korth, M.L. Marconi, D.A. Mendis, F.A. Krueger, A.K. Richter, R.P. Lin, D.L. Mitchell, K.A. Anderson, C.W. Carlson, H. Rème, J.A. Sauvaud and C. d'Uston, Nature, 337 (1989) 52.

[6] F.P. Losing, Can. J. Chem., 50 (1972) 3971.

[7] P.J. Ausloos and S.G. Lias, J. Am. Chem. Soc., 103 (1981) 6505.

[8] A. Cameron, J. Leszczynky, M.C. Zerner and B. Weiner, J. Phys. Chem., 93 (1989) 139.

[9] L. Radom, P.C. Hariharan, J.A. Pople and P.v. R. Schleyer, J. Am. Chem. Soc., 98 (1976) 10.

[10] K. Raghavachari, R.A. Whiteside, J.A. Pople and P.v.R. Schleyer, J. Am. Chem. Soc., 103 (1981) 5649.

[11] M.W. Wang and L. Radom, J. Am. Chem. Soc., 111 (1989) 6976.

[12] A.C. Hopkinson and M.H. Lien, J. Am. Chem. Soc., 108 (1986) 2843.

[13] R. Breslow and J.T. Groves, J. Am. Chem. Soc., 92 (1970) 988.

[14] T. Takada and K. Ohno, Bull. Chem. Soc. Jpn., 52 (1979) 334.

[15] N. Craig, J. Pranata, S.J. Reiganum, J.R. Sprague and P.S. Stevens, J. Am. Chem. Soc., 108 (1986) 4378.

[16] T.K. Ha, F. Graf and H. Gunthard, J. Mol. Struct., 15 (1973) 335.

[17] Y.-G. Buyn, S. Saebo and C.U. Pittman, Jr., J. Am. Chem. Soc., 113 (1991) 3689.

[18] Y. Xie and J.E. Boggs, J. Chem. Phys., 90 (1989) 4320.

[19] T.J. Lee, A. Willets, G.F. Jeffrey and N.C. Handy, J. Chem. Phys., 90 (1989) 4330.

[20] T.D. Norden, S.W. Staley, W.H. Taylor and M.D. Harmony, J. Am. Chem. Soc., 108 (1986) 7912.

[21] N.C. Craig, R.K.-Y. Lai, L.G. Matus, J.H. Miller and S.L. Palfrey, J. Am. Chem. Soc., 102 (1980) 36.

[22] N.C. Craig, R.K.-Y. Lai, K.W. Penfield and I.W. Levin, J. Phys. Chem., 84 (1980) 899.

[23] N.C. Craig, N.C. Fleming and J. Pranata, J. Am. Chem. Soc., 107 (1985) 7324.
[24] M.H. Lien and A.C. Hopkinson, J. Mol. Struct. (Theochem) 165 (1988) 37.

[25] T. Clark, J. Chandrasekar, G.W. Spitznagel and P.v.R. Schleyer, J. Comput. C'hem., 4 (1983) 294.

[26] M.J. Frisch, M. Head-Gordon, G.W. Trucks, J.B. Foresman, H.B. Schlegel, K. Raghavachari, M. Robb, M. Binkley, C. Gonzalez, D.J. Defrees, D.J. Fox, R.A. Whiteside, R. Seegler, C.F. Melius, J. Baker, R.L. Martin, L.R. Kahn, J.J.P. Stewart, S. Topiol and J.A. Pople, GAusian 90, revision F, Gaussian, Inc., Pittsburgh PA, 1990.

[27] R. Krishnan, J.S. Binkely, R. Seeger and J.A. Pople, J. Chem. Phys., 72 (1980) 4244.

[28] M.D.G. Faria and R. Fausto, TRANSFormer (version 1.0), Departamento de Quimica, Universidade de Coimbra, Portugal, 1990.

[29] M.D.G. Faria and R. Fausto, build-g and vibrat, Departamento de Química, Universidade de Coimbra, Portugal, 1990 (These programs incorporate several routines from programs GMAT and FPERT, H Fuher, V.B Kartha, K.G. Kidd, P.J. Krueger and H.H. Mantsch, Natl. Res. Counc. Can. Bull., 15 (1976) 1).

[30] R.S. Grev and H.F. Schaefer, J. Chem. Phys., 91 (1989) 7305.

[31] D.B. Chesnut and K.D. Moore, J. Chem. Phys., 96 (1992) 7188.

[32] M. Gussoni, M.N. Ramos, C. Castiglioni and G. Zerbi, Chem. Phys. Lett., 142 (1987) 515.

[33] W.T. King and G.B. Mast, J. Phys. Chem., 80 (1980) 2521.

[34] U. Dinur, Chem. Phys. Lett., 166 (1990) 211.

[35] M.H. Lien and A.C. Hopkinson, J. Mol Struct. (Theochem), 121 (1985) 1.

[36] A.T. Peretta and V.W. Laurie, J. Chem. Phys., 62 (1975) 246.

[37] K.R. Ramaprasad, V.W. Laurie and N.C. Craig, J. Chem. Phys., 64 (1977) 3896.

[38] L. Pierce and V. Dobyns, J. Am. Chem. Soc., 84 (1962) 2651 .

[39] J.L. Hencher and S.H. Bauer, J. Am. Chem. Soc., 89 (1967) 5527.

[40] K.B. Wiberg and K.E. Laidig, J. Am. Chem. Soc., 109 (1987) 5935 .

[41] H.A. Bent, Chem. Rev., 61 (1961) 275. 